\title{
Layer-Specific Refinement of Visual Cortex Function after Eye Opening in the Awake Mouse
}

\author{
Jennifer L. Hoy and Cristopher M. Niell \\ Institute of Neuroscience, University of Oregon, Eugene, Oregon 97403
}

The laminar structure and conserved cellular organization of mouse visual cortex provide a useful model to determine the mechanisms underlying the development of visual system function. However, the normal development of many receptive field properties has not yet been thoroughly quantified, particularly with respect to layer identity and in the absence of anesthesia. Here, we use multisite electrophysiological recording in the awake mouse across an extended period of development, starting at eye opening, to measure receptive field properties and behavioral-state modulation of responsiveness. We find selective responses for orientation, direction, and spatial frequency at eye opening, which are similar across cortical layers. After this initial similarity, we observe layer-specific maturation of orientation selectivity, direction selectivity, and linearity over the following week. Developmental increases in selectivity are most robust and similar between layers 2-4, whereas layers 5 and 6 undergo distinct refinement patterns. Finally, we studied layer-specific behavioral-state modulation of cortical activity and observed a striking reorganization in the effects of running on response gain. During week 1 after eye opening, running increases responsiveness in layers 4 and 5, whereas in adulthood, the effects of running are most pronounced in layer $2 / 3$. Together, these data demonstrate that response selectivity is present in all layers of the primary visual cortex (V1) at eye opening in the awake mouse and identify the features of basic V1 function that are further shaped over this early developmental period in a layer-specific manner.

Key words: development; gain modulation; mouse; orientation selectivity; receptive field; V1

\section{Introduction}

Studies of mouse primary visual cortex can serve as a powerful tool to causally link developmental mechanisms to normal cellular and circuit function in the adult visual system. The majority of this work has focused primarily on understanding the mechanisms underlying retinotopy and ocular dominance (OD) plasticity (for review, see Huberman et al., 2008; Morishita and Hensch, 2008; Cang and Feldheim, 2013; Triplett, 2014). However, the visual system must also appropriately wire up circuits to support the emergence of many basic receptive field (RF) properties, including orientation selectivity (OS), direction selectivity (DS), spatial frequency (SF) preference, and linearity. Thus far, only a handful of studies have quantified the early maturation of a subset of these properties in mouse V1 (Fagiolini et al., 2003; Rochefort et al., 2011; Wang et al., 2010, 2013; Ko et al., 2013, 2014). No single study has systematically quantified the simultaneous development of these RF properties in the awake mouse as a function of cortical layer in monocular V1. Such a study would

\footnotetext{
Received July 31, 2014; revised Nov. 14, 2014; accepted Dec. 5, 2014.

Author contributions: J.L.H. and C.M.N. designed research; J.L.H. performed research; J.L.H. and C.M.N. analyzed data; J.L.H. and C.M.N. wrote the paper.

This work was supported by National Institutes of Health Grants 1R01EY023337 and 1DP2EY023190 (C.M.N.) and 1F32EY024179 (J.L.H.). We thank Drs. Sunil Gandhi, Denise Piscopo, and Wayne Tschetter for comments on this manuscript and members of the Niell laboratory for helpful discussions.

The authors declare no competing financial interests.

Correspondence should be addressed to Cristopher Niell, Institute of Neuroscience, 1254 University of Oregon, Eugene, 0R 97403. E-mail: cniell@uoregon.edu.

DOI:10.1523/JNEUROSCI.3174-14.2015

Copyright $\odot 2015$ the authors $\quad 0270-6474 / 15 / 353370-14 \$ 15.00 / 0$
}

serve as a foundation for understanding the molecular and cellular developmental mechanisms that give rise to these fundamental features of visual system function.

The visual cortex of mice, as well as other mammals, comprises multiple layers, each of which is defined by a distinct set of functional properties, subcortical inputs, and intracortical connectivity (Ringach et al., 2002; Niell and Stryker, 2008; Clemens et al., 2012). Furthermore, selective responses, such as DS and OS, emerge in multiple layers, and there is evidence in mammals that this selectivity arises within each layer via distinct developmental mechanisms (Trachtenberg et al., 2000; Trachtenberg and Stryker, 2001; Clemens et al., 2012). It remains unknown whether distinct mechanisms contribute to the development of basic RF properties and V1 function across cortical layers in the mouse. Careful examination of the development of the spatialtemporal structure of the RF and selectivity of neurons throughout V1 as a function of layer may provide the information necessary to begin to address this outstanding question.

Here, we systematically quantify RF structure and a core set of V1 response properties as a function of layer in awake, quiescent mice over development between eye opening and adulthood. This work is further distinguished from existing studies in that we additionally measure the emergence of mature patterns of behavioral-state modulation of response gain and local field potential (LFP) power (Niell and Stryker, 2010). Overall, we find that all measured RF properties are present in each cortical layer of V1 at eye opening. We also observe that the spatial structure of the RF of linear responses in V1 at eye opening closely resembles 
A

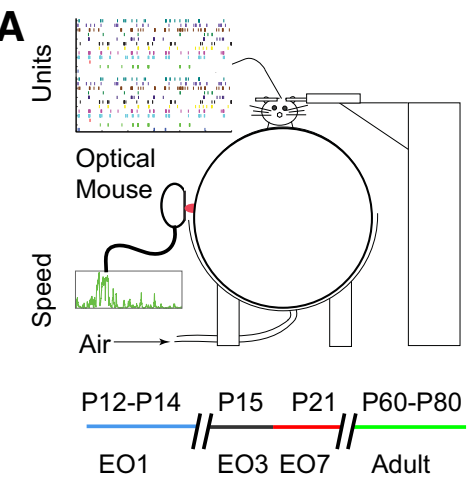

C

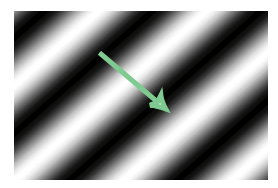

$\mathbf{E}$
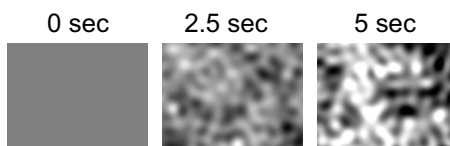

sec

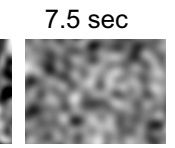

Figure 1. Experimental setup and visual stimuli. A, Top, Awake mice of all ages are headfixed atop a Styrofoam ball suspended by air. Ball motion is detected and transmitted via two optical mice. Bottom, Developmental time points: $\mathrm{E} 01(N=13), \mathrm{E} 03(N=11), \mathrm{E} 07(N=10)$, and adult $(N=11)$. $B$, Schematic of custom multisite silicon probe used for recording (contains 64 sites total). C, Drifting sinusoidal gratings of 12 directions and six SFs. D, Drifting bars of eight directions and two contrasts (black or white) against gray background. $\boldsymbol{E}$, Contrast-modulated noise movies.

those measured in the adult. However, significant refinement of selectivity is seen specifically in layers $2-4$ in the week after eye opening, whereas the majority of response selectivity observed in layers 5 and 6 does not change significantly after eye opening. Interestingly, although behavioral state affects response gain already at eye opening, the laminar profile of this effect switches over development.

In general, we find evidence for layer-specific developmental differences in both RF properties and behavioral-state modulation of V1 responsiveness. DS, RF shape, response gain, and LFP modulation significantly develop in a layer-specific manner over
A
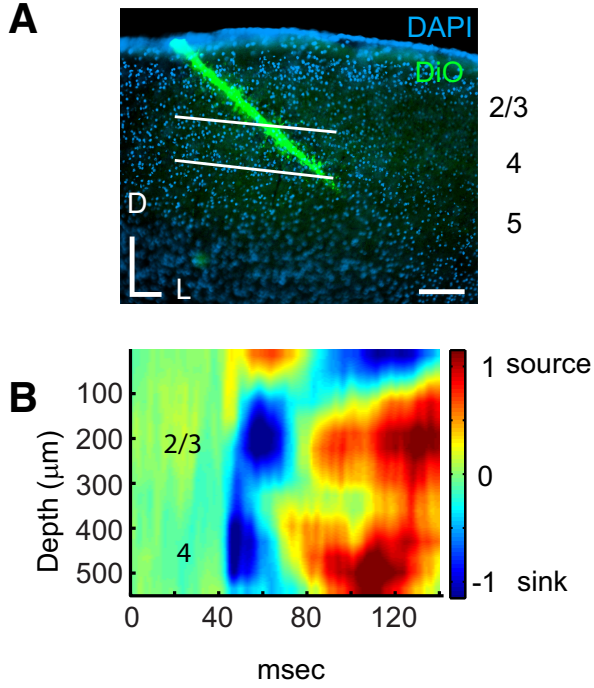

Figure 2. Layer identification. $A$, Example DAPI-stained (blue) coronal section from a juvenile brain. Dorsal (D) and lateral (L) orientations noted. Layer 4 is outlined with white bars, and the recording track is shown in green (Di0 coating of electrode). Scale bar, $100 \mu \mathrm{m} . \boldsymbol{B}$, CSD analysis of recording shown in $\boldsymbol{A}$. Blue represents current sinks and red current sources. Layer 4 sites were located via a prominent early sink. Data are from an E04 juvenile.

early development from eye opening. These findings argue that, despite a substantial degree of cortical function already established at eye opening, there are important layer-specific differences in the development of monocular V1 function from eye opening through adulthood.

\section{Materials and Methods}

All studies were conducted with approved protocols from the University of Oregon Institutional Animal Care and Use Committees, in compliance with National Institutes of Health guidelines for the care and use of experimental animals.

In vivo physiology. Recordings were performed on awake female and male C57BL/6J mice, ages P12 up to 2.5 months of age. Animals were maintained on a 14/10 h light/dark cycle. All recordings were performed 3-4 h before the start of their normal dark (awake) cycle. This facilitated comparable epochs of moving and stationary behaviors at all ages.

We observed that eye opening could occur between P12 and P14, and therefore pups in this range were monitored every $12 \mathrm{~h}$ to determine the precise time of eye opening. Pups within $0-24 \mathrm{~h}$ of eye opening were
A

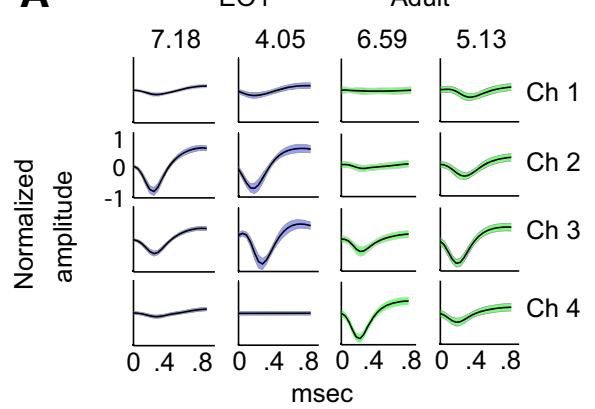

B

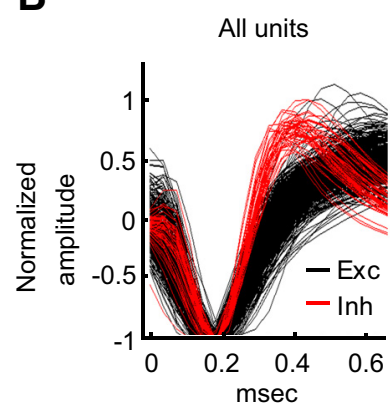

C

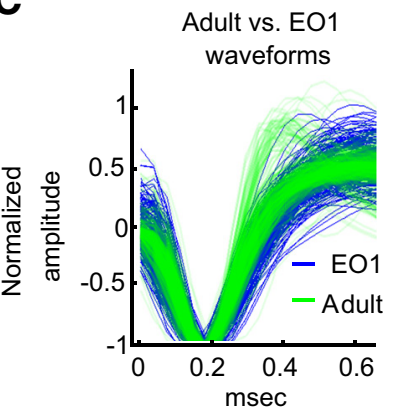

Figure 3. Unit isolation and waveform characterization. A, Two representative isolated units each from the E01 juveniles (left columns, blue) and adults (right columns, green). The normalized mean waveform is shown with solid black lines, and the SD is depicted as colored shading on either side of the mean. The waveform is plotted on all four channels (Ch1-Ch4) of a given virtual tetrode used in the study. The signal to noise ratio (SNR) of the waveform amplitude on the peak channel is provided at the top of each column. Exemplars were drawn randomly from all units that met the criteria for good isolation. $\boldsymbol{B}$, Waveforms of visually responsive units clustered into two distinct categories, colored red (narrow) and black (broad), based on trough-to-peak distance and peak-to-trough height ratio as shown previously (Niell and Stryker, 2008). The average spike waveform for each unit is plotted aligned to its minimum and normalized by trough depth. Exc, Excitatory; Inh, inhibitory. $\boldsymbol{C}$, The same waveforms as classified and shown in $\boldsymbol{B}$, labeled as a function of age. E01, Blue; adult, green. Note the absence of narrow spiking units in E01 mice. E01, $n=227$ total units; adult, $n=283$ total units. 
pooled in the EO1 (day 1 of eye opening) developmental group and similarly for EO3 (3-4 $\mathrm{d}$ after eye opening) and EO7 (7-8 d after eye opening).

Before recording, all animals underwent one $10 \mathrm{~min}$ handling session before head-plate implant and two 10 min sessions after implant. This handling was followed up with one $10 \mathrm{~min}$ "practice" session in which the animal was attached to the spherical treadmill recording apparatus described previously (Niell and Stryker, 2010) and initially developed by Dombeck et al. (2007) (Fig. 1A).

To facilitate head fixation during recording, custom stainless steel head-plate implants were cemented to the skull between 2 and $7 \mathrm{~d}$ before the recording session as described previously (Niell and Stryker, 2010). Briefly, adults and pups were anesthetized with isoflurane in oxygen ( $3 \%$ induction, $1.0-1.5 \%$ maintenance), warmed with a heating pad at $37^{\circ} \mathrm{C}$ (adult) to $39^{\circ} \mathrm{C}$ (pups), and given subcutaneous injections of $0.1 \mathrm{ml}$ (pups) or $0.25 \mathrm{ml}$ (adults) of lactated Ringer's solution and carprofen $(5 \mathrm{mg}$ / $\mathrm{kg}$ ). In all animals, the scalp and fascia from bregma to just behind lambda were removed, and the skull was covered with a thin layer of cyanoacrylate (VetBond; WPI) before attaching the head plate with dental acrylic (OrthoJET; Lang Dental Manufacturing). The well of the head plate was filled with silicone elastomer (Kwik-Sil; WPI) to protect the skull before recordings. Head plates were stable on pups for up to $3 \mathrm{~d}$, after which skull growth and their mother's grooming behavior decreased stability of the implant.

On the day of recording, the animals were anesthetized to perform a craniotomy over the visual cortex. The craniotomies were $\sim 1 \mathrm{~mm}$ in diameter and centered at $2.5 \mathrm{~mm}$ lateral of midline and $1 \mathrm{~mm}$ anterior of the posterior suture. The brain surface was covered in 1.5\% agarose (Sigma-Aldrich) in sterile saline and then capped with silicone elastomer during a $3-4 \mathrm{~h}$ recovery. To begin the recording session, the animal was placed in the head-plate holder on the free-floating ball and allowed to habituate for $15 \mathrm{~min}$ in low light. After removing the protective agarose and silicone plug, the ground wire was set, and a fresh layer of 1.5\% agarose in saline was applied to the well. A multisite electrode (A2X32-5mm-25-200-177A64; Neuronexus Technologies), coated with $\mathrm{DiO}$ (Invitrogen) to allow post hoc track recovery, was then inserted through the craniotomy and overlying agarose. We used a custom 64channel electrode arranged in a two-shank, linear configuration, with each shank having 32 sites separated by $25 \mu \mathrm{M}$. The electrode was placed at an angle of $45^{\circ}$ relative to the cortical surface and inserted to an appropriate depth. After insertion, agarose was added to stabilize the electrode, and it was allowed to settle for $40 \mathrm{~min}$. Targeting the penetrations in this way ensured sampling of all cortical layers across groups. Only one penetration per animal was made, but up to two recording sessions per animal were performed in approximately two-thirds of the animals by advancing the electrode until all sites had moved past previous recording depths. All units stably isolated over the recording were included in subsequent analysis, with specific response properties calculated offline.

Recordings sessions typically lasted $1.5 \mathrm{~h}$. Stimulus presentation timing was optimized previously to ensure that each stimulus was presented
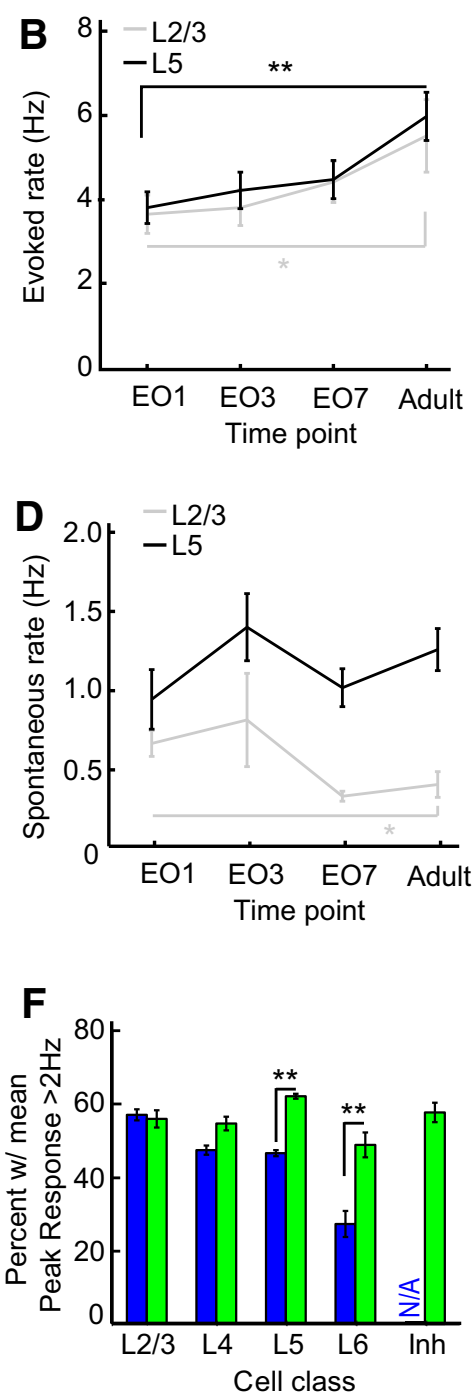

Figure 4. Comparison of firing rates and responsiveness between E01 juveniles and adults. $\boldsymbol{A}$, Median evoked firing rates compared as a function of cell class and development (E01 juveniles, blue bars vs adults, green bars). Excitatory units are classified class; adults, $n=283$ units total, $n=40,49,136,28$, and 30 by cell class. L, Layer (laminar location of broad waveform excitatory units); Inh, inhibitory (narrow waveform units). Error bars are \pm SEM calculated via bootstrap; same $n$ as in $\boldsymbol{A}$; Wilcoxon's rank-sum in layers 2/3 (gray) and 5 (black). Wilcoxon's rank-sum test, Bonferroni's correction for multiple comparisons. $\boldsymbol{C}$, Median 作 stimulus. Error bars represent the $95 \%$ confidence intervals calculated via the Clopper-Pearson method, ${ }^{* *} p<0.01, \chi^{2}$ test, Bonferroni's correction. In all panels, ${ }^{*} p<0.05,{ }^{* *} p<0.01,{ }^{* * *} p<0.001$.

five to seven times in each behavioral state (Niell and Stryker, 2010). After the recording session, mice were deeply anesthetized in 3\% isoflurane and killed via cervical dislocation. The brains were then fixed whole in $4 \%$ PFA (Electron Microscopy Sciences) overnight at room temperature. Brains were subsequently sectioned and mounted in Flouromount G with DAPI (Southern Biotechnology). We imaged the DiO electrode tracks on a Zeiss Axio Imager 2 to confirm that penetrations were specific to monocular V1 (Antonini et al., 1999; Altamura et al., 2007; Niell and Stryker, 2008) and to determine the location of the electrode tips relative to the cortical layer.

Visual stimuli. Visual stimuli were presented as described previously (Niell and Stryker, 2008). Briefly, stimuli were generated in MATLAB (MathWorks) using the Psychophysics Toolbox extension (Brainard, 


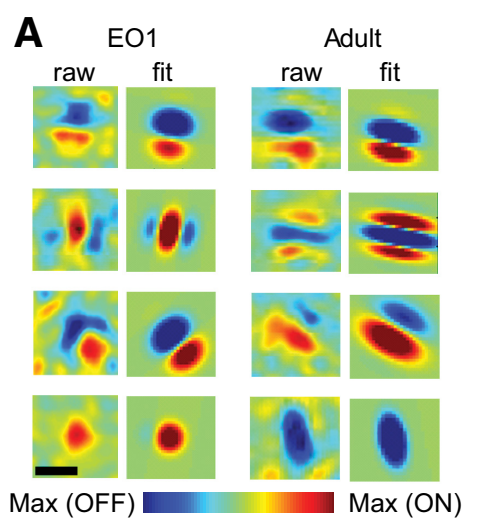

a.u.
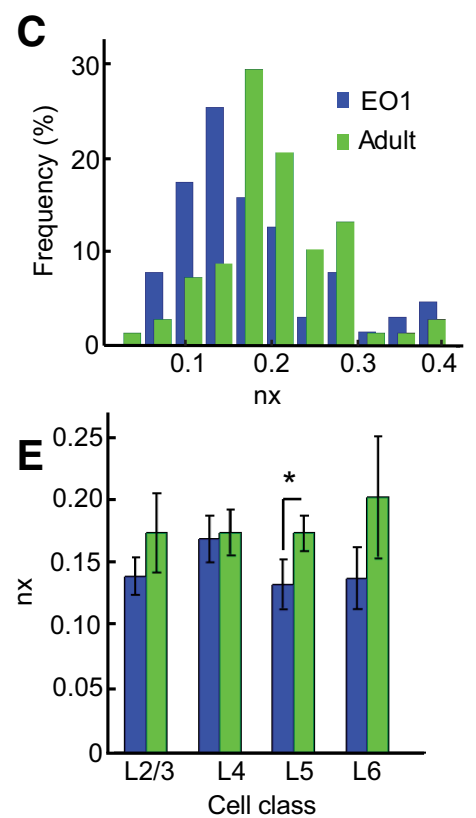

G

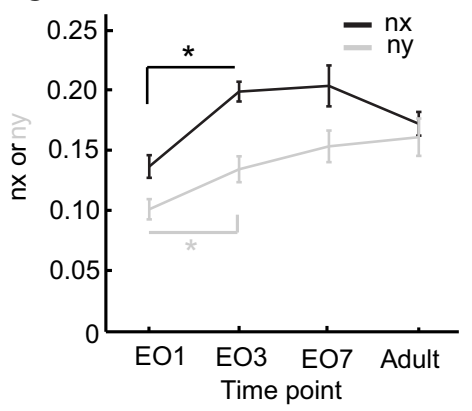

B

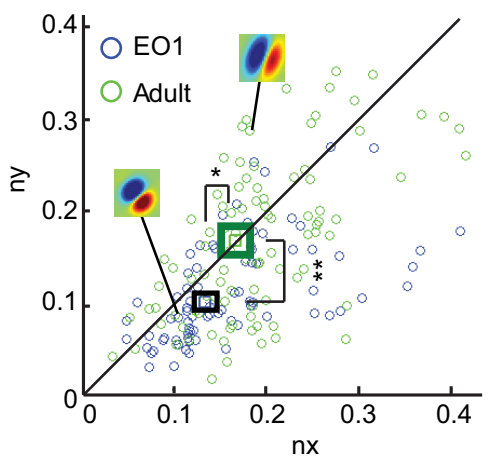

D
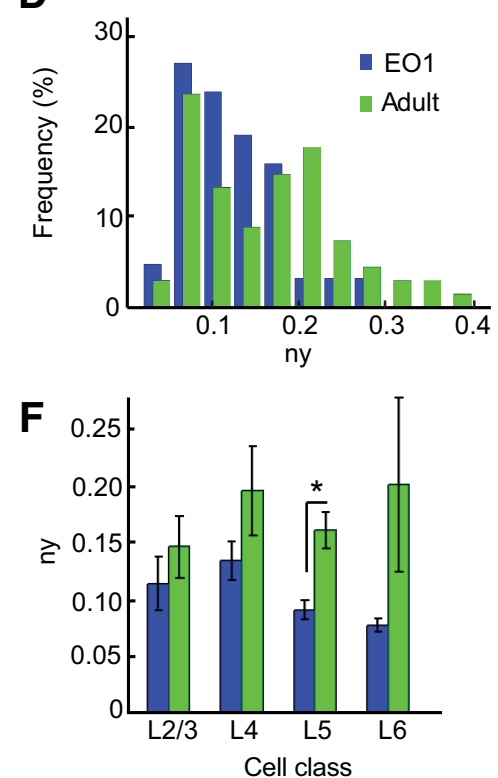

Figure 5. Development of spatial RF structure. $\boldsymbol{A}$, Representative STAs generated from reverse correlation to white-noise stimuli (Niell and Stryker, 2008). Raw STAs are shown to the left of their Gabor fit. Red regions indicate an ON subfield, and blue indicates an OFF subfield; peak intensity within each color represents the maximum response compared with baseline (green; see color bar). Scale bar, $20^{\circ}$ of visual space. $\boldsymbol{B}$, Dimensionless geometric description, $n x$ and $n y$, of the RF structure for units accurately fit by Gabor function (Ringach, 2002). E01: blue circles, $n=80$ STAs, center of black box is the median, edges of box are \pm SEM; adult: green circles, $n=95$ STAs, center of dark green box is median, edges are \pm SEM. ${ }^{*} p<0.05,{ }^{* *} p<0.01$, KS test. Example STAs are overlaid onto the plot and associated with their $n x$ and $n y$ values. $\boldsymbol{C}$, Distribution of the population of $n x$ measures from well fit STAs. D, ny distribution. $\boldsymbol{E}$, Median $n x$ values for STAs categorized by layer. E01: blue bars, $n=22,25,30$, and 3; adult: green bars, $n=26,21,43$, and 5. ${ }^{*} p<0.05$, Wilcoxon's rank-sum test with Bonferroni's correction. F, Median ny values for STAs categorized by layer organized as in C. G, Overall median $n x$ and $n y$ values \pm SEM across developmental time points. E03, $n=45 ; \mathrm{E} 07, n=62$.

1997; Pelli, 1997) and displayed with gamma correction on a monitor (Planar SA2311W, $30 \times 50 \mathrm{~cm}, 60 \mathrm{~Hz}$ refresh rate). The screen was placed $25 \mathrm{~cm}$ from the mouse's eye, subtending $\sim 60-75^{\circ}$ visual space. Monitor mean luminance was measured to be $70 \mathrm{~cd} / \mathrm{m}^{2}$. The monitor was raised or lowered up to $10 \mathrm{~cm}$, depending on the hand-mapped RF location of multiunit activity.

For LFP measurements, we presented fulllength drifting bars $\left(5^{\circ}\right.$ width, $30^{\circ} / \mathrm{s}$ velocity, eight directions, two contrasts). To characterize selectivity of neural responses with single-unit recordings, we presented drifting sinusoidal gratings of $1.5 \mathrm{~s}$ duration at $100 \%$ contrast, with temporal frequency of $2 \mathrm{~Hz}$, SF of $0.01,0.02,0.04,0.08,0.16,0.32$, and $0 \mathrm{cy}-$ cles $/^{\circ}$ (cpd) in 12 evenly spaced directions. Gratings with a temporal frequency of $2 \mathrm{~Hz}$ were chosen to compare responses with those from the study by Niell and Stryker (2008), which showed a preferred temporal frequency of $2 \mathrm{~Hz}$ in adults. However, we also confirmed that there were no differences in the OS index (OSI), DS index (DSI), or SF preference when temporal frequency was varied between 1,2 , and $4 \mathrm{~Hz}$ in layers $2-5$ of juveniles (OSI: $0.65 \pm$ $0.08,0.58 \pm 0.07,0.66 \pm 0.07, p=0.830,1$ vs 2 $\mathrm{Hz}, p=0.674,2$ vs $4 \mathrm{~Hz}$; DSI: $0.13 \pm 0.05$, $0.18 \pm 0.05,0.18 \pm 0.06, p=0.684,1$ vs $2 \mathrm{~Hz}$, $p=0.865,2$ vs $4 \mathrm{~Hz}$; and SF preference: $0.05 \pm$ $0.02,0.04 \pm 0.01,0.03 \pm 0.01, p=0.923,1$ vs 2 $\mathrm{Hz}, p=0.657,2$ vs $4 \mathrm{~Hz}, n=30$, Wilcoxon's rank-sum test, Bonferroni's correction). The stimulus conditions were randomly interleaved, and a gray blank condition (mean luminance) was included to estimate the spontaneous firing rate. To identify cortical layers via current source density (CSD) analysis, as in the study by Niell and Stryker (2008), we presented a contrast-reversing square checkerboard $(0.04 \mathrm{cpd}$, square-wave reversing at 0.5 $\mathrm{Hz}$ ). The spatial RF was estimated by the spike-triggered average (STA) in response to Gaussian 1/f noise movies as described previously.

Data acquisition and analysis. Signals were acquired using a System 3 workstation (Tucker Davis Technologies) and analyzed with custom routines written in MATLAB.

As in the study by Niell and Stryker (2010), movement signals from the optical mice were acquired at up to $300 \mathrm{~Hz}$ and integrated at 100 ms intervals (Mx310; Logitech). We used these measurements to calculate the net physical displacement of the top surface of the ball and calculate the average speed of the animal during a stimulus presentation. Stationary trials were classified as ball speeds $<0.7 \mathrm{~cm} / \mathrm{s}$ and moving $>0.7 \mathrm{~cm} / \mathrm{s}$ for all age groups. The 0.7 $\mathrm{cm} / \mathrm{s}$ separates the central peak at $\sim 0 \mathrm{~cm} / \mathrm{s}$ ( stationary) from the wide distribution of moving speeds for all developmental groups tested, as well as adults. This threshold is slightly lower than that used by Niell and Stryker (2010) (1 $\mathrm{cm} / \mathrm{s}$ ) to account for overall lower speeds in young mice.

For LFP analysis, the extracellular signal was filtered from 1 to $300 \mathrm{~Hz}$ and sampled at 1.5 $\mathrm{kHz}$. The power spectrum was computed using multi-taper estimation in MATLAB with the Chronux package (Mitra and Pesaran, 1999; Mitra and Bokil, 2007), using a 3 s sliding window and three to five tapers. Spectra were normalized for presentation by applying a $1 / \mathrm{f}$ correction (Sirota et al., 2008). 
For single-unit activity, the extracellular signal was filtered from 0.7 to $7 \mathrm{kHz}$ and sampled at $25 \mathrm{kHz}$. Spiking events were detected online by voltage threshold crossing, and a $1 \mathrm{~ms}$ waveform sample on four adjacent recording surfaces constituting a "virtual" tetrode was acquired around the time of threshold crossing. Single-unit clustering and spike waveform analysis was performed as described previously (Niell and Stryker, 2008) with a combination of custom software in MATLAB and Klusta-Kwik (Harris et al., 2000). Quality of separation was determined based on the following criteria: (1) contained $<0.1 \%$ of spikes within a $1.0 \mathrm{~ms}$ interspike interval; (2) at least one feature of a given spike had to form a visually identifiable well segregated cluster in a projection onto a two-dimension feature subspace, confirmed by the computed $L$ ratio (Schmitzer-Torbert et al., 2005); (3) the peak amplitude of a unit remained stable over the entire recording session; and (4) the peak amplitude of a unit had a signal-to-noise ratio (SNR) of $>2$ (mean amplitude at the peak is two times greater than the SD of the amplitude). In fact, the median SNR for adult units and EO juveniles was $5.95 \pm$ 0.09 and $5.29 \pm 0.23$, respectively. Representative isolated units along with their SNR are shown in Figure $3 A$. Typical recordings yielded $\sim 10-12$ single units across each shank of the electrode. Most units appeared predominantly on a single recording site, although units often contributed a signal below the voltage threshold on neighboring sites, which allowed improved unit discrimination.

Units were classified as narrow or broad spiking based on properties of their average waveforms at the electrode site with largest amplitude. As detailed in the study by Niell and Stryker (2008), two parameters-(1) height of the positive peak relative to the initial negative trough and (2) time from the minimum of the initial trough to maximum of the following peak-were sufficient to generate two linearly separable clusters corresponding to narrowspiking (putative inhibitory) and broadspiking (putative excitatory) neurons. These clusters were separated using $K$ means.

Layer identity was derived independently and corroborated from both CSD analysis (Figure $2 B$ ) and recovery of electrode tracks labeled by $\mathrm{DiO}$ in histological sections (Fig. $2 A)$. In both cases, all sites were given a specific layer assignment based on their position along the probe relative to the probe tip and the geometry of the penetration angle.

The average spontaneous rate for each unit was calculated by averaging the rate over all blank condition presentations. Responses at each orientation and SF were calculated by av-

eraging the spike rate during the $1.5 \mathrm{~s}$ presentation of stimulus type and subtracting the spontaneous rate during gray screen presentations. We first determined the neurons that were visually responsive by calculating the $t$ statistic (mean evoked firing divided by SE) across trials for the optimal stimulus. Units with $t>2$ were considered reliably visually responsive. To ensure robust assessment of RF and tuning properties, we imposed an additional more stringent requirement for those units entered into all subsequent analyses: that units have an average peak evoked firing rate, across trials of the optimal stimulus, of $>2 \mathrm{~Hz}$.
A

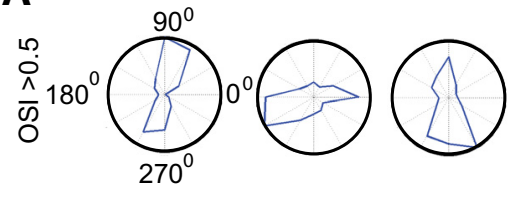

B
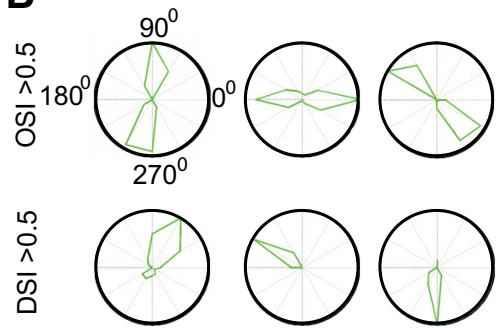

C

E

G

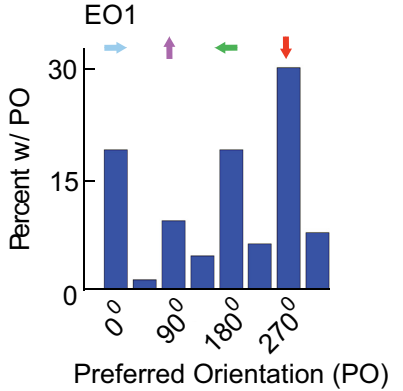

H
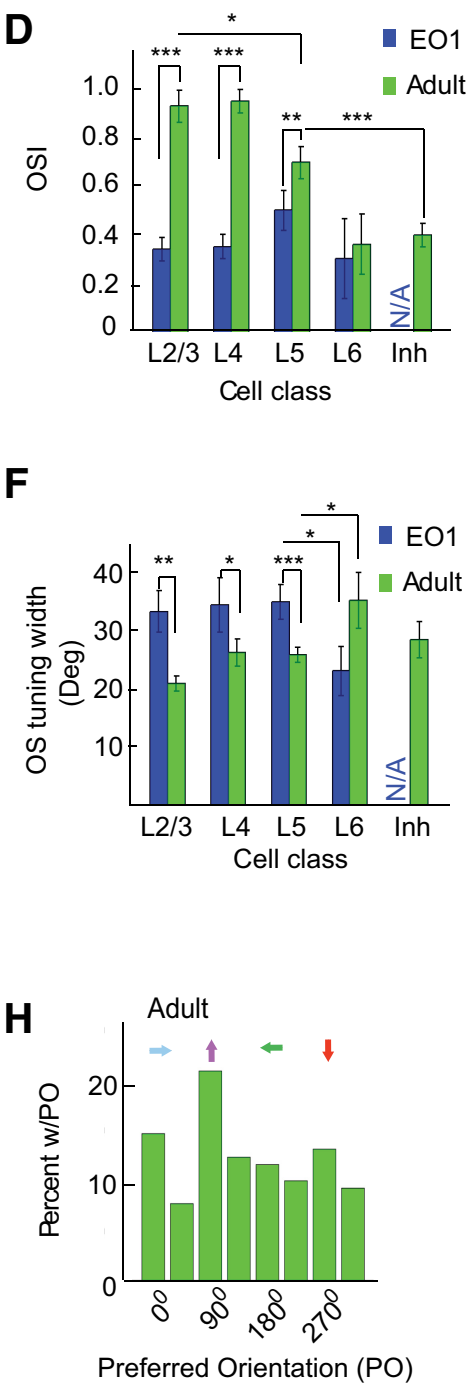

Preferred Orientation (PO)

Figure 6. OS significantly matures between eye opening and adulthood in layers 2-5. $A, B$, Representative orientation-tuned responses or direction-tuned responses from E01 juveniles $(\boldsymbol{A})$ and adults $(\boldsymbol{B})$. $\boldsymbol{C}$, Distribution of OSI values from E01 juveniles (blue) and adults (green). D, Median OSI of the same data in C; error bars are \pm SEM. ${ }^{*} p<0.05,{ }^{* *} p<0.01,{ }^{* * *} p<0.001$, Wilcoxon's rank-sum test; E01 in blue, adults in green. N/A, Not applicable because of lack of data in class. $\boldsymbol{E}, \boldsymbol{F}$, Same organization as in $\boldsymbol{C}$ and $\boldsymbol{D}$, showing median orientation tuning width. $\mathbf{G}, \boldsymbol{H}$, Histogram of the preferred orientation of units from $\mathrm{E} 01(\boldsymbol{G})$ and adults $(\boldsymbol{H})$. Colored arrows mark the cardinal axes and indicate the orientation and direction of grating motion. Inh, Inhibitory.

Tuning curves were analyzed following the methods of Niell and Stryker (2008). Briefly, the preferred orientation was determined by averaging the response across all SFs and calculating half the complex phase of the value. The orientation tuning curve was constructed for the SF that gave peak response at this orientation. Given this fixed preferred orientation, $\theta$ pref, the tuning curve was fitted as the sum of two Gaussians centered on $\theta$ pref and $\theta$ pref $+\pi$, of different amplitudes A1 and A2 but equal width $\sigma$, with a constant baseline B. From this fit, we calculated two metrics: (1) an OSI representing the ratio of the tuned 
versus untuned component of the response; and (2) the width of the tuned component. The OSI was calculated as the depth of modulation from the preferred orientation to its orthogonal orientation $\theta$ ortho $=$ $\theta$ pref $+\pi / 2$, as $\left(R_{\text {pref }}-R_{\text {ortho }}\right) /\left(R_{\text {pref }}+R_{\text {ortho }}\right)$. Tuning width was the half-width at half-maximum of the fit above the baseline, $R_{\text {ortho }}$. We also included the global measures of orientation and direction selectivity as represented by $1-$ Circular variance $(1-$ CirVar $)$ and $1-$ direction space circular variance (DirCirVar). These values were computed as in the study by Mazurek et al. (2014), after Ringach et al. (2002) and Batschelet (1981): $\quad L_{\text {ori }}=\quad\left|\frac{\sum_{k} R\left(\theta_{k}\right) \exp \left(2 i \theta_{k}\right)}{\sum_{k} R\left(\theta_{k}\right)}\right|, \quad L_{\text {dir }}$ $=\left|\frac{\sum_{k} R\left(\theta_{k}\right) \exp \left(i \theta_{k}\right)}{\sum_{k} R\left(\theta_{k}\right)}\right|, 1-$ CirVar $=L_{\text {ori }}$, and $1-$ DirCirVar $=L_{\mathrm{dir}}$, where $R\left(\theta_{k}\right)$ is the response to angle $\theta_{k}$.

Statistics. Comparisons of medians and variation around the median are performed via Wilcoxon's rank-sum test unless noted otherwise. SEM is obtained via bootstrapping (data sampled $1000 \times$ ). Differences in frequency of categorical observations between groups are determined via $\chi^{2}$, and differences in distributions of continuous, quantitative data between groups are determined via Kolmogrov-Smirnov (KS) test. To test for the modality of a distribution, we used the Hartigan's dip test that probes for deviations from unimodality (Hartigan and Hartigan, 1985). The Lillifor test is used to determine distribution skew. All data represent data from all animals in each group: $\mathrm{EO} 1, N=13, n=227$; EO3, $N=11$, $n=295$; EO7, $N=11, n=225$; and adult, $N=10, n=283$. When necessary, Holm-Bonferroni test is applied to correct for multiple comparisons of data. For the comparisons of ratios, SEMs are computed via a bootstrapping procedure, and significance was determined via Wilcoxon's signed-rank tests.

\section{Results}

Our goal was to quantify the early development of neuronal response properties and behavioral-state modulation as a function of layer in monocular V1 of the awake mouse. To accomplish this goal, we measured V1 function over several stages of development from the onset of eye opening to adulthood in awake mice (Fig. 1A). We used a custom multisite silicon electrode to record neuronal responses while delivering stimuli designed to measure canonical cortical responses (Fig. 1B-E; Niell and Stryker, 2008). Recordings were obtained between the first day of eye opening (EO1) and $\sim 2$ months of age (adult). Initial experiments specifically compared the EO1 group ( $n=227$ units in 13 animals) with the adult group ( $n=283$ units in 11 animals) to first understand which visual responses significantly changed over development and whether we could detect layer-specific developmental differences. In follow-up experiments, we compared these measures with two intermediate developmental time points, EO3 $(N=11)$ and EO7 $(N=10)$ to determine the time course over which significant changes occurred.

\section{Laminar location, cell-type identity, and responsiveness}

To identify the laminar location of recording sites within V1, we recovered electrode tracks through histology and reconstructed site localization based on the geometry of the probe relative to the penetration angle at the surface of cortex (Fig. 2A; see Materials and Methods). Localization to monocular V1 was confirmed simultaneously. CSD analysis (Fig. 2B) and qualitative observations of previously identified layer-specific activity patterns in the adult confirmed the site localization identified via histology (Niell and Stryker, 2008).

Well isolated single units (Fig. 3A; see Materials and Methods) were then classified based on their spike waveform parameters. As shown previously (Niell and Stryker, 2008), clustering reliably separated two distinct classes of waveforms: narrow-spiking and
Table 1.

\begin{tabular}{|c|c|c|c|c|}
\hline Cell class & E01 & E03 & E07 & $\begin{array}{l}\text { Adults } \\
\text { (>2 months) }\end{array}$ \\
\hline \multicolumn{5}{|c|}{ Spontaneous firing rate } \\
\hline Excitatory $2 / 3$ & $0.67 \pm 0.08$ & $0.81 \pm 0.29$ & $0.33 \pm 0.3$ & $0.41 \pm 0.08$ \\
\hline Excitatory 4 & $1.04 \pm 0.15$ & $0.67 \pm 0.09$ & $0.60 \pm 0.20$ & $0.67 \pm 0.20$ \\
\hline Excitatory 5 & $0.94 \pm 0.19$ & $1.4 \pm 0.21$ & $1.02 \pm 0.11$ & $1.26 \pm 0.13$ \\
\hline Excitatory 6 & $0.88 \pm 0.68$ & $0.83 \pm 0.26$ & $0.67 \pm 0.21$ & $1.73 \pm 0.41$ \\
\hline Inhibitory all & $\mathrm{N} / \mathrm{A}$ & $\mathrm{N} / \mathrm{A}$ & $6.06 \pm 1.07$ & $5.22 \pm 1.63$ \\
\hline \multicolumn{5}{|l|}{ Evoked firing rate } \\
\hline Excitatory $2 / 3$ & $3.66 \pm 0.30$ & $3.81 \pm 0.29$ & $4.42 \pm 0.33$ & $5.51 \pm 0.58$ \\
\hline Excitatory 4 & $4.48 \pm 0.56$ & $4.24 \pm 0.19$ & $4.18 \pm 0.29$ & $5.61 \pm 0.49$ \\
\hline Excitatory 5 & $3.81 \pm 0.25$ & $4.22 \pm 0.26$ & $4.48 \pm 0.30$ & $5.97 \pm 0.35$ \\
\hline Excitatory 6 & $2.83 \pm 0.71$ & $3.82 \pm 0.40$ & $4.37 \pm 0.38$ & $7.73 \pm 1.09$ \\
\hline Inhibitory all & $N / A$ & $\mathrm{~N} / \mathrm{A}$ & $6.48 \pm 0.75$ & $7.42 \pm 1.09$ \\
\hline \multicolumn{5}{|l|}{ OSI } \\
\hline Excitatory $2 / 3$ & $0.34 \pm 0.04$ & $0.55 \pm 0.07$ & $0.86 \pm 0.06$ & $0.93 \pm 0.07$ \\
\hline Excitatory 4 & $0.35 \pm 0.05$ & $0.61 \pm 0.09$ & $0.66 \pm 0.09$ & $0.95 \pm 0.05$ \\
\hline Excitatory 5 & $0.50 \pm 0.08$ & $0.47 \pm 0.02$ & $0.72 \pm 0.07$ & $0.69 \pm 0.07$ \\
\hline Excitatory 6 & $0.30 \pm 0.16$ & $0.71 \pm 0.07$ & $0.81 \pm 0.18$ & $0.36 \pm 0.13$ \\
\hline Inhibitory all & $\mathrm{N} / \mathrm{A}$ & $\mathrm{N} / \mathrm{A}$ & $0.38 \pm 0.09$ & $0.41 \pm 0.06$ \\
\hline \multicolumn{5}{|l|}{$1-$ CirVar } \\
\hline Excitatory $2 / 3$ & $0.19 \pm 0.03$ & $0.30 \pm 0.05$ & $0.48 \pm 0.03$ & $0.58 \pm 0.08$ \\
\hline Excitatory 4 & $0.16 \pm 0.04$ & $0.33 \pm 0.05$ & $0.38 \pm 0.06$ & $0.53 \pm 0.05$ \\
\hline Excitatory 5 & $0.24 \pm 0.04$ & $0.27 \pm 0.03$ & $0.34 \pm 0.04$ & $0.36 \pm 0.04$ \\
\hline Excitatory 6 & $0.16 \pm 0.07$ & $0.41 \pm 0.05$ & $0.40 \pm 0.05$ & $0.3 \pm 0.08$ \\
\hline Inhibitory all & $\mathrm{N} / \mathrm{A}$ & $\mathrm{N} / \mathrm{A}$ & $0.22 \pm 0.05$ & $0.17 \pm 0.04$ \\
\hline \multicolumn{5}{|l|}{ OS tuning width } \\
\hline Excitatory $2 / 3$ & $32.89 \pm 3.48$ & $28.94 \pm 2.78$ & $25.82 \pm 2.27$ & $20.81 \pm 1.39$ \\
\hline Excitatory 4 & $34.03 \pm 4.54$ & $30.14 \pm 1.59$ & $27.29 \pm 1.88$ & $25.95 \pm 2.40$ \\
\hline Excitatory 5 & $34.50 \pm 3.10$ & $34.81 \pm 2.24$ & $23.94 \pm 1.76$ & $25.57 \pm 1.42$ \\
\hline Excitatory 6 & $22.88 \pm 5.19$ & $32.90 \pm 2.76$ & $29.45 \pm 3.25$ & $34.79 \pm 4.41$ \\
\hline Inhibitory all & $N / A$ & $\mathrm{~N} / \mathrm{A}$ & $34.31 \pm 6.56$ & $27.71 \pm 2.77$ \\
\hline \multicolumn{5}{|l|}{ DSI } \\
\hline Excitatory $2 / 3$ & $0.19 \pm 0.04$ & $0.28 \pm 0.04$ & $0.44 \pm 0.07$ & $0.17 \pm 0.05$ \\
\hline Excitatory 4 & $0.19 \pm 0.04$ & $0.24 \pm 0.03$ & $0.27 \pm 0.08$ & $0.25 \pm 0.08$ \\
\hline Excitatory 5 & $0.18 \pm 0.02$ & $0.20 \pm 0.03$ & $0.21 \pm 0.05$ & $0.21 \pm 0.02$ \\
\hline Excitatory 6 & $0.16 \pm 0.07$ & $0.40 \pm 0.07$ & $0.36 \pm 0.12$ & $0.09 \pm 0.05$ \\
\hline Inhibitory all & $\mathrm{N} / \mathrm{A}$ & $\mathrm{N} / \mathrm{A}$ & $0.09 \pm 0.03$ & $0.15 \pm 0.03$ \\
\hline \multicolumn{5}{|l|}{1 - DirCirVar } \\
\hline Excitatory $2 / 3$ & $0.20 \pm 0.04$ & $0.28 \pm 0.05$ & $0.39 \pm 0.07$ & $0.22 \pm 0.05$ \\
\hline Excitatory 4 & $0.16 \pm 0.04$ & $0.17 \pm 0.03$ & $0.30 \pm 0.08$ & $0.28 \pm 0.08$ \\
\hline Excitatory 5 & $0.19 \pm 0.03$ & $0.20 \pm 0.03$ & $0.17 \pm 0.05$ & $0.19 \pm 0.02$ \\
\hline Excitatory 6 & $0.20 \pm 0.07$ & $0.31 \pm 0.07$ & $0.39 \pm 0.12$ & $0.13 \pm 0.05$ \\
\hline Inhibitory all & $\mathrm{N} / \mathrm{A}$ & $\mathrm{N} / \mathrm{A}$ & $0.13 \pm 0.03$ & $0.11 \pm 0.01$ \\
\hline
\end{tabular}

SF preference

Excitatory $2 / 3$

Excitatory 4

Excitatory 5

Excitatory 6

Inhibitory all

Percentage linear

Excitatory $2 / 3$

Excitatory 4

Excitatory 5

Excitatory 6

Inhibitory all

Gain modulation

Excitatory $2 / 3$

Excitatory 4

Excitatory 5

Excitatory 6

$\begin{array}{lllll}0.037 \pm 0.005 & 0.044 \pm 0.006 & 0.049 \pm 0.009 & 0.043 \pm 0.008\end{array}$

$\begin{array}{lllll}0.034 \pm 0.003 & 0.040 \pm 0.004 & 0.041 \pm 0.006 & 0.053 \pm 0.009\end{array}$

$0.035 \pm 0.002 \quad 0.038 \pm 0.004 \quad 0.041 \pm 0.006 \quad 0.035 \pm 0.003$

$\begin{array}{llll}0.054 \pm 0.012 & 0.035 \pm 0.005 & 0.035 \pm 0.011 & 0.018 \pm 0.008\end{array}$

N/A N/A $\quad 0.040 \pm 0.012 \quad 0.035 \pm 0.012$

$\begin{array}{llll}39.58 \pm 3.17 & 36.96 \pm 3.33 & 49.02 \pm 2.85 & 62.07 \pm 4.67\end{array}$

$22.22 \pm 3.48 \quad 36.25 \pm 1.94 \quad 38.98 \pm 2.59 \quad 47.22 \pm 4.08$

$27.42 \pm 2.56 \quad 24.27 \pm 1.58 \quad 31.88 \pm 2.28 \quad 24.07 \pm 1.51$

$\begin{array}{llll}44.45 \pm 15.02 & 26.67 \pm 5.09 & 19.05 \pm 6.80 & 47.37 \pm 7.64\end{array}$

$\mathrm{N} / \mathrm{A} \quad \mathrm{N} / \mathrm{A}$

$43.64 \pm 1.36 \quad 37.45 \pm 9.32$

Inhibitory all

$1.12 \pm 0.15$

$1.43 \pm 0.26$

$1.25 \pm 0.14$

$1.98 \pm 0.21$

$1.91 \pm 0.24$

$1.89 \pm 0.17$

$2.33 \pm 0.24$

$1.31 \pm 0.19$

$\begin{array}{llll}1.98 \pm 0.23 & 1.97 \pm 0.19 & 1.64 \pm 0.23 & 1.29 \pm 0.13\end{array}$

$\begin{array}{llll}2.05 \pm 0.24 & 2.55 \pm 0.20 & 1.31 \pm 0.22 & 1.51 \pm 0.41\end{array}$

Results are shown as median \pm SEM. 

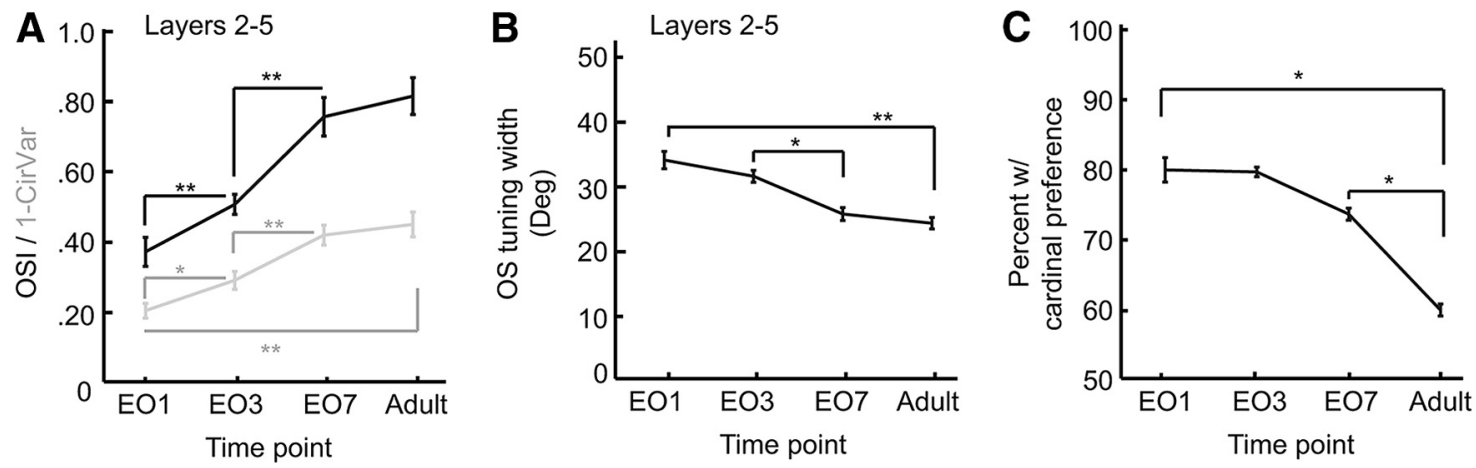

Figure 7. Changes in OS over development. A, Median OSI \pm SEM (black) and median 1 - CirVar \pm SEM (gray) compared between four developmental time points: E01, E03, E07, and adults. ${ }^{*} p<0.05,{ }^{* *} p<0.01$, Wilcoxon's rank-sum test, Bonferroni's correction. $\boldsymbol{B}$, Median tuning width of orientation-selective responses (OSI $\left.>0.5\right) \pm$ SEM compared as in $A$. ${ }^{* *} p<0.01$, Wilcoxon's rank-sum test, Bonferroni's correction. C, Percentage of responses selective for the cardinal directions \pm Clopper-Pearson confidence intervals. ${ }^{*} p<0.05, \chi^{2}$ test, Bonferroni's correction.

broad-spiking waveforms (Fig. 3B, red and black, respectively). However, we observed no narrow-spike waveforms among units recorded at EO1 (Fig. $3 C$ ). In our adult group, $\sim 11 \%$ (30 of 283 units) of visually responsive units had classical, narrow waveforms. The narrow waveforms did not make up a significant percentage of the responsive population compared with the adult group until $7 \mathrm{~d}$ after eye opening (EO3 fraction of population with narrow waveform: $1 \%, n=130, \chi=8.72, p=$ 0.0031 ; EO7 fraction with narrow waveform: $12 \%, n=121, \chi=0.0821, p=0.774)$.

To characterize unit responsiveness over development, we calculated an SNR for the firing rate response to repeated presentations of the preferred stimulus (Fig. 4E; see Materials and Methods). The fraction of cells that were deemed responsive by this statistical measure increases over development in layers 4-6 and slightly decreases in layers $2 / 3$ between EO1 and adulthood. Although this measure determines which units have a statistically significant visual response, responses meeting this criterion could still be weak and not suitable for calculating tuning curves and RFs. Therefore, we used a second criterion - a firing rate of at least $2 \mathrm{~Hz}$ to the optimal stimulus-to select units for subsequent analysis. The distribution of cells meeting this criterion is shown in Figure $4 F$.

Visually evoked firing rates in layers $2 / 3,5$, and 6 were higher in adults than at eye opening (Fig. $4 A, B$ ). Additionally, the spontaneous firing rate specifically in layers $2 / 3$ decreased over development (Fig. 4C,D). Thus, overall visual responsiveness of cortex, both in terms of the number of responsive neurons and the peak firing rate, increases after eye opening in a layer-specific manner.

\section{RF structure}

Previous studies have shown that simple cells in V1 have a characteristic spatial RF structure that is well described by a subset of two-dimensional Gabor functions. Notably, this RF organization is shared across mice, cats, and monkeys (Jones and Palmer, 1987; Ringach, 2002; Niell and Stryker, 2008). To determine when this structure is established over development, we obtained the STA of the response of each unit to stochastic noise (Fig. $1 E$; see Materials and Methods) and fit these STAs to a two-dimensional Gabor function (Ringach, 2002; Niell and Stryker, 2008; Ko et al., 2013). STAs in which $>60 \%$ of the signal variance was accounted for by the Gabor fit were included for analysis. We compared STA structure using the scale-free parameters $n x$ and $n y$, which express the width and length of the fitted Gabor function in terms of the number of cycles of the underlying sinusoidal grating (Ringach, 2002). 

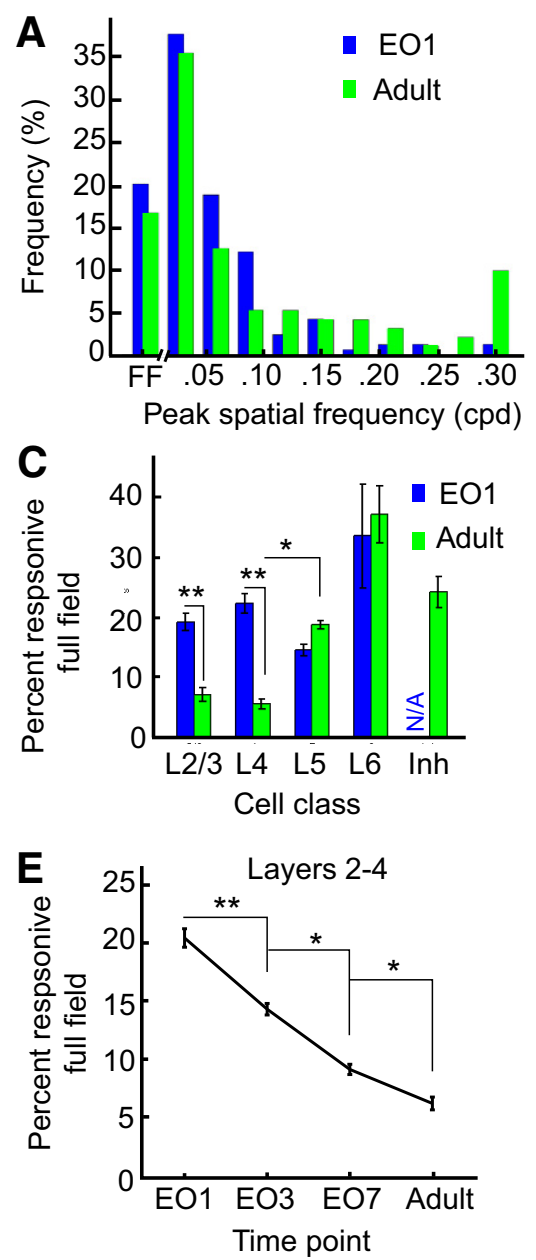

B
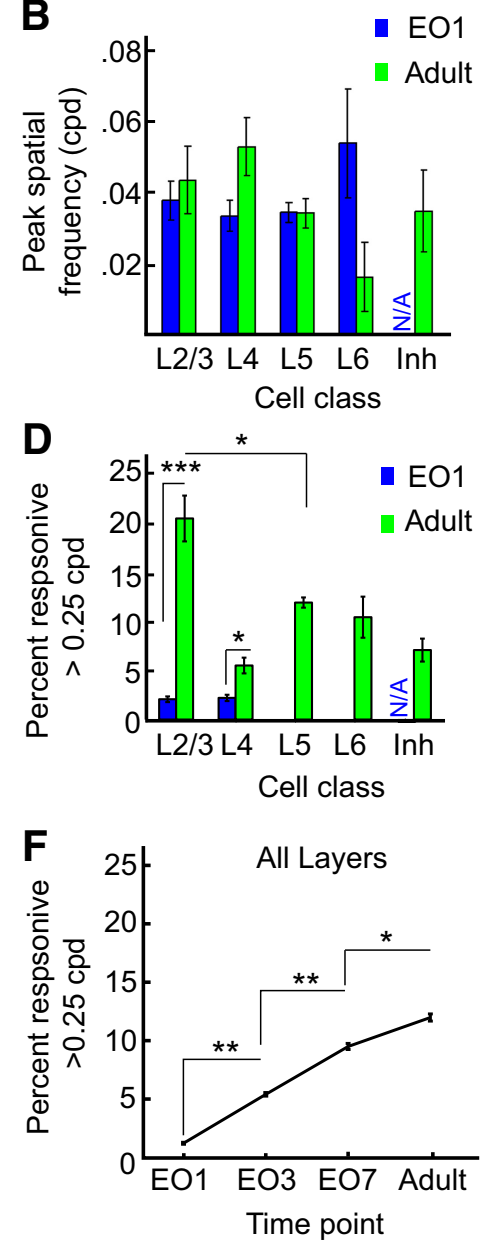

Figure 9. SF tuning is refined in all layers between eye opening and adulthood. $\boldsymbol{A}$, Distribution of peak SF preferences. E01, Blue; adult, green. FF, Responsive to full-field flash. There is a significant difference in distribution between ages, $p<0.05, \mathrm{KS}$ test. $\boldsymbol{B}$, Median peak SF for all responsive units grouped by cell class and age. E01, Blue; adult, green. Error bars are $\pm S E M, n$.s. in all cases, Kruskal-Wallis test and post hoc planned comparisons, Wilcoxon's rank-sum test with Bonferroni's correction. C, Percentage of units responsive to full-field flashes in each layer. E01, blue; adults, green. Error bars are Pearson-Clopper confidence intervals. ${ }^{*} p<0.05,{ }^{* *} p<0.01, \chi^{2}$ test, Bonferroni's correction. $\boldsymbol{D}$, Percentage of responses to grating with SFs higher than $0.25 \mathrm{cpd}$. Error bars are Pearson-Clopper confidence intervals. ${ }^{*} p<0.05,{ }^{* * *} p<0.001, \chi^{2}$ test. $\boldsymbol{E}, \boldsymbol{F}$, Developmental changes in full-field responses $(\boldsymbol{E})$ and responses to SFs above $0.25 \mathrm{cpd}(\boldsymbol{F}) .{ }^{*} p<0.05,{ }^{* *} p<0.01, \chi^{2}$ test, Bonferroni's correction.

RF structure, as measured by STA, was established at eye opening in all cortical layers. We found no significant differences in the fraction of units with STAs well described by Gabor functions over development (EO1: $49 \pm 8 \%, n=164$; adult: $50 \pm 7 \%, n=191 ; p=0.0939, \chi^{2}$ test). In contrast, the median $n x$ and $n y$ values for the EO1 group were significantly smaller than the adults (Fig. 5A), indicating decreased complexity of spatial RF structure at eye opening.

When measures of $n x$ and $n y$ were segregated by layer, significant differences were only observed in layer 5 after correction for multiple comparisons (Fig. 5E,F). Overall median $n x$ and $n y$ values reached adult-like levels by EO3 (Fig. 5G). Although we found these differences in RF organization over development, the median size of the RFs overall, as measured by the Gaussian envelope of the Gabor function, was not significantly different between the EO1 and adult groups (data not shown). Thus, although total RF size did not change over development, the spatial structure within this area did refine, with a slight shift toward more subregions and a significant elongation of the RF.

\section{Layer-specific maturation of} orientation and direction selectivity

We next characterized the selectivity of V1 neurons for specific visual properties throughout the time course of development. At eye opening, drifting sinusoidal gratings elicited orientationand direction-selective responses (Fig. $6 A)$, consistent with previous findings that these fundamental properties are established before visual experience (Fagiolini et al., 2003; Rochefort et al., 2011; Ko et al., 2013). However, there are important differences in OS between $\mathrm{EO} 1$ animals and adults (Fig. 6, compare $A, B$ ). Notably, OS significantly increases over development as indicated by developmental changes in the median OSI and median orientation tuning width of responsive units (Fig. 6C-F; Table 1). We find the same developmental increase (approximately threefold) in OS by comparing a global measure of OS, 1 - CirVar (Mazurek et al., 2014; Fig. 7A; Table 1).

Consistent with previous findings in the anesthetized adult mouse (Niell and Stryker, 2008), we find that OS is higher in layers $2-4$ relative to layer 5 and inhibitory units (Fig. $6 C, D$; Table 1). Interestingly, this difference in OS between excitatory cells from layers $2-6$ is not yet manifested at EO1 (Fig. 6C,D; Table 1). Another notable aspect of the development of OS was that units at EO1 exhibited a bias for orientations along the cardinal axes (Fig. 6G; Table 1). This bias, which was observed across layers, was significantly reduced by adulthood (Fig. 6H; Table 1).

In examining intermediate time points, we found that OSI and OS tuning width change most rapidly over week 1 of eye opening, peaking at adult-like levels by EO7 for excitatory responses (Fig. $7 A, B$; Table 1). The OSI for inhibitory responses also did not change significantly between EO7 and adulthood (EO7, $0.38 \pm 0.09$; adult, $0.41 \pm 0.06$; n.s., Wilcoxon's rank-sum test; Table 1$)$. In contrast, the bias toward cardinal axes persisted throughout week 1 after eye opening, suggesting relatively late maturation of this feature of selectivity (Fig. $7 C$ ). Overall, this suggests that OS is primarily refined in week 1 after eye opening in layers $2-5$ but that changes must continue to balance the representation of all orientations.

We next characterized DS, the preference for one particular direction of motion for a given oriented grating. Although recent work has shown a lack of significant developmental changes in DS in superficial layers of V1 in anesthetized mice (Rochefort et al., 2011), this has not yet been examined in awake mice or in deeper layers. Our experiments reveal a significant change in DS in layers $2 / 3$ that occur specifically between EO1 and EO7 (Fig. $8 C$; Table 1). Unexpectedly, we find that DS significantly decreases between $\mathrm{EO} 7$ and adulthood in layers $2 / 3$. In comparison, we find no significant differences in DS over any stage of development in layer 4 

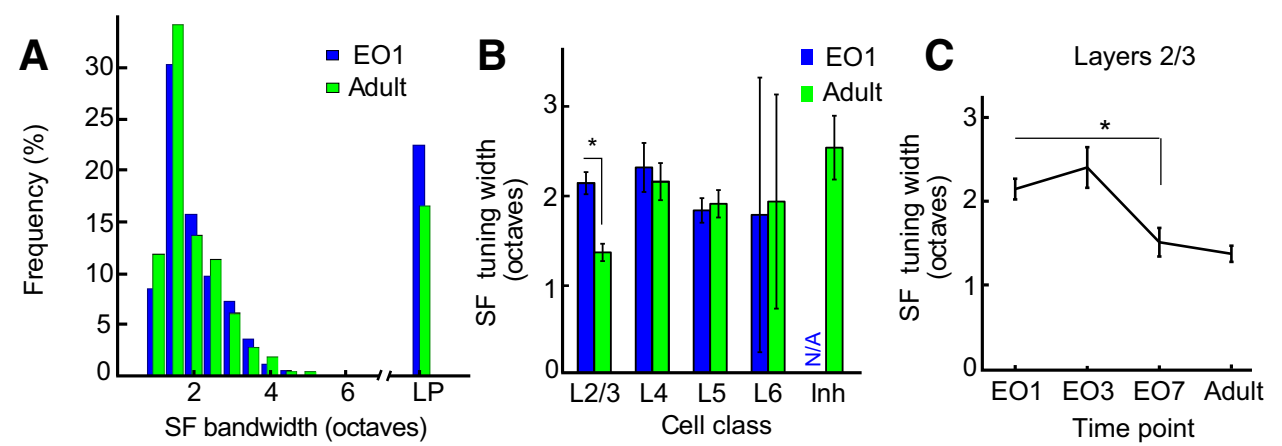

Figure 10. Changes in SF tuning width between eye opening and adulthood. $A$, Distribution of SF tuning width in octaves from each group. E01, blue; adult, green. LP, Low pass. Distributions are not significantly different (n.s.), KS test. B, Median SF tuning width by cell class and age. E01, Blue; adult, green. Error bars are \pm SEM. ${ }^{*} p<0.025$, Wilcoxon's rank-sum test, Bonferroni's correction. $\mathrm{N} / \mathrm{A}$, Not applicable because of lack of data in class. C, Developmental changes in the median SF tuning width. ${ }^{*} p<0.025$, Wilcoxon's rank-sum test, Bonferroni's correction. Inh, Inhibitory.
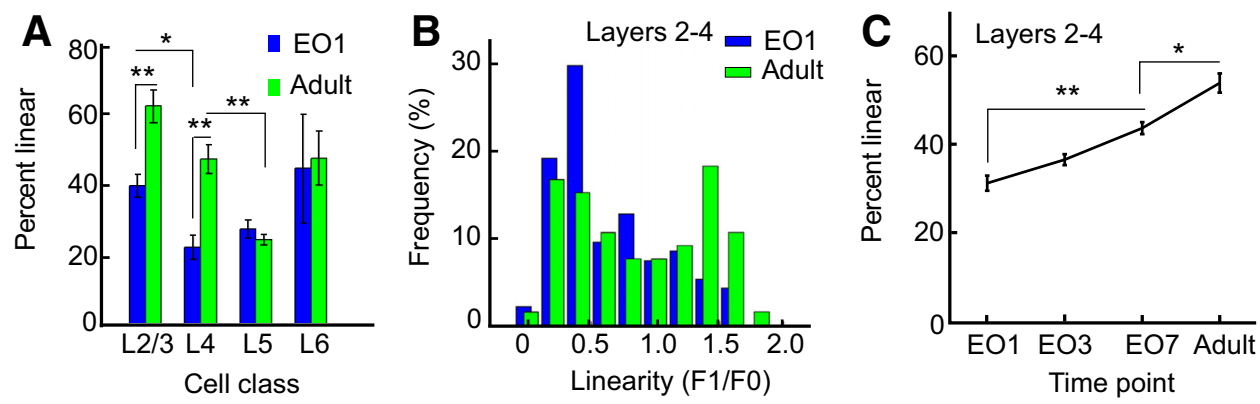

Figure 11. Linearity of responses to drifting sinusoidal gratings over development. $A$, Percentage of responses classified as linear $\left(F_{1} / F_{0}>1\right)$ within each layer at E01 (blue) and adult (green) stages. Error bars are Pearson-Clopper confidence intervals. ${ }^{*} p<0.05,{ }^{* *} p<0.01, \chi^{2}$ test, Bonferroni's correction. $\boldsymbol{B}$, Distribution of the $F_{1} / F_{0}$ ratio for layers $2-4$ from E01 (blue) and adult (green) groups. The two distributions are significantly different, $p<0.05$, KS test. C, Developmental changes in linearity in layers $2-4$ compared between all developmental groups: E01, E03, E07, and adult. ${ }^{*} p<0.05,{ }^{* *} p<0.01, \chi^{2}$ test, Bonferroni's correction.

(Fig. 8D). These specific observations of DS also hold true when measuring 1 - DirCirVar (Fig. 8C,D; Table 1). Together, our data argue that there are important differences in the development of DS in the mouse visual cortex. However, future work will require both layer-specific examination of this development and the inclusion of data from 1 week after eye opening.

\section{SF preference and response linearity significantly mature after eye opening}

One hallmark of selectivity in mammalian V1 is preference for particular SFs (SF preference). Furthermore, the range of SFs over which neurons respond sets constraints on cortical visual acuity. Similar to OS and DS, SF preference across a range of SFs is observed in each layer at eye opening (Fig. 9). However, the distribution of SF preferences in EO1 juveniles was skewed toward lower SFs and was significantly different from the distribution of SF preference in the adult (EO1 vs adult; $n=164$ of 220; $p=0.0017$, KS test; Fig. 9A). Despite this difference in the distribution, the median SF preference was not significantly different between $\mathrm{EO} 1$ juveniles and adults in any layer after correction for multiple comparisons (Fig. 9B; Table 1).

To probe the differences more closely, we examined the populations responding to either full-field flicker or high SFs. We observe a decrease in the population responding to full-field stimuli in layers 2-4 between EO1 juveniles and adults (Fig. 9C). This change is accompanied by the emergence of a significant population of responses to high SF gratings $(>0.25 \mathrm{cpd})$ in all layers (Fig. 9D). These layer-specific shifts in the population response underlie the overall shift in SF preferences seen in V1 development. Interestingly, we also find that this developmental progression results in layer-specific differences in responses to low and high SFs in the adult. In layers $2-4$, there are significantly fewer responses to full-field flashes relative to layers 5 and 6 , whereas responses to high-frequency gratings are also significantly higher in layers $2 / 3$ relative to all other layers in the adult. These developmental changes in SF preference occurred steadily between eye opening and adulthood (Fig. 9E,F; Table 1). Concurrent with changes in the preferred SF over development, SF tuning width significantly narrowed within layers $2 / 3$ (Fig. 10A-C).

V1 neurons were characterized originally as simple or complex based on their ability to be defined by segregated ON and OFF subregions (Hubel and Wiesel, 1962, 1968). This aspect of RF organization, reflecting the linearity of spatial summation, has been shown to vary across the layers of cortex and is often measured by the periodicity of response to drifting gratings $\left(F_{1} / F_{0}\right.$ ratio; Skottun et al., 1991; Mechler and Ringach, 2002). Therefore, we measured developmental changes in linearity of responses to drifting gratings over development. As predicted by our ability to measure linear STAs, we find linear responses to gratings $\left(F_{1} / F_{0}>1\right)$ already established at the time of eye opening (Fig. 11). Furthermore, response linearity is already significantly enhanced in layer $2 / 3$ relative to layers 4 and 5 at EO1 $(39.58 \pm 3.17$ vs $22.22 \pm 3.48 \%$, layers $2 / 3$ and 4 , respectively; $p<0.05, \chi^{2}$ test; Fig. $11 A$ ). In adults, we observe a larger proportion of linear responses in layers $2-4$ relative to layer 5 ( $47.22 \pm 4.08$ vs $24.07 \pm 1.51 \%$, layers 4 and 5 , respectively; $p<0.01, \chi^{2}$ test; Fig. $11 A$ ), consistent with previous studies of anesthetized mouse V1 (Niell and Stryker, 2008). Given this layer difference, we specifically compared developmental changes in layers 2-4 between age groups. We found that the overall proportion of linear responses increases between EO1 and the adult in layers 2-4 $(p<$ 
0.05, KS test; Fig. 11B; Table 1). Furthermore, linearity increases over each stage of development examined here (Fig. 11C; Table 1). Thus, together with the STA data, we find that RFs do have distinct ON and OFF regions at eye opening but that there is an increase in the spatial segregation of these regions over an extended period of development after eye opening.

\section{Modulation of visual responses by behavioral state refines over week 1 after eye opening}

Previous studies of V1 function in the awake mouse have shown that cortical activity is modulated as a function of behavioral state (Niell and Stryker, 2010). In particular, locomotion induces an increase in visually evoked neuronal firing rate and enhances the amplitude of a high-frequency oscillation in the gamma range observed in the LFP. Because these features of cortical activity may reflect the output of important computations that affect visual processing (Heeger, 1992; Vidyasagar et al., 1996; Sompolinsky and Shapley, 1997; Cardin et al., 2009; Katzner et al., 2011), we monitored their development from eye opening. Importantly, recent studies have found that mouse pups exhibit spontaneous bouts of quadruped locomotion by P10 (Clarke and Still, 2001; Dehorter et al., 2011). However, several aspects of the gait and velocity during locomotion do not fully mature until P24 (Clarke and Still, 2001). Consistent with these findings, we find that P12P14 mouse pups exhibit clear shifts in locomotive state on the trackball during recordings (Figs. 12A, 13A, bottom gray trace). Although we observed a similar threshold for locomotion in EO1 juveniles compared with adults (Fig. 12A), their speeds during locomotive bouts were significantly slower than adults (EO1, $4.74 \pm 0.01 \mathrm{~cm} / \mathrm{s}$ vs adults, $7.57 \pm 0.02 \mathrm{~cm} / \mathrm{s} ; p<0.001$, KS test).

A previous study primarily investigated locomotor induced modulation of firing rates in layer 2/3 (Niell and Stryker, 2010). Here we determined the time line for the emergence of these activities across all cortical layers in V1. In the adults, we find that firing rate is significantly modulated in layers $2-5$. However, the strength of modulation is strongest for those units in layer $2 / 3$ (ratios, $1.98 \pm 0.21$ vs $1.31 \pm 0.19$, layers $2 / 3$ and 4 in the adult, respectively; Wilcoxon's rank-sum test, $p<0.05$; Fig. 12B). Surprisingly, we find dramatic layer-specific differences in response gain between eye opening and adulthood (Fig. 12B). The increase in visually evoked firing rate during locomotion is absent in layer $2 / 3$ at eye opening ( $1.12 \pm 0.15$ vs 1 ; n.s., Wilcoxon's signed-rank test; Fig. 12B; Table 1). Instead, locomotion induces increases in response gain specifically in layers 4 and 5 (1.91 \pm 0.24 and $1.98 \pm 0.23$ vs 1 , layers 4 and 5 , respectively; Wilcoxon's signedrank test, $p<0.05$; Fig. 12B; Table 1). The juvenile laminar pattern of behavioral-state modulation of gain reverses between EO7 and adulthood (Fig. 12C; Table 1), resulting in the mature pattern of large gain changes seen in layer $2 / 3$.

We also observe significant maturation of locomotor-induced changes in LFP power between eye opening and the adult (Fig. 13). In adults, locomotion induces a decrease in power at frequencies between 7 and $10 \mathrm{~Hz}$ and an increase in a narrow band of LFP power between 50 and $60 \mathrm{~Hz}$ (gamma), consistent with previous reports (Fig. 13C,D; Niell and Stryker, 2010). Several features of this characteristic activity are not observed at EO1 during locomotive bouts (Fig. 13, compare $A, C$ ). Instead, the most prominent feature induced by locomotion in juveniles is a broad increase in power over a lower-frequency range of 20-40 Hz. This suggests that the characteristic modulations of LFP activity are immature at eye opening.

Given our findings for layer-specific differences in firing rate modulation over development, we further analyzed LFP activity
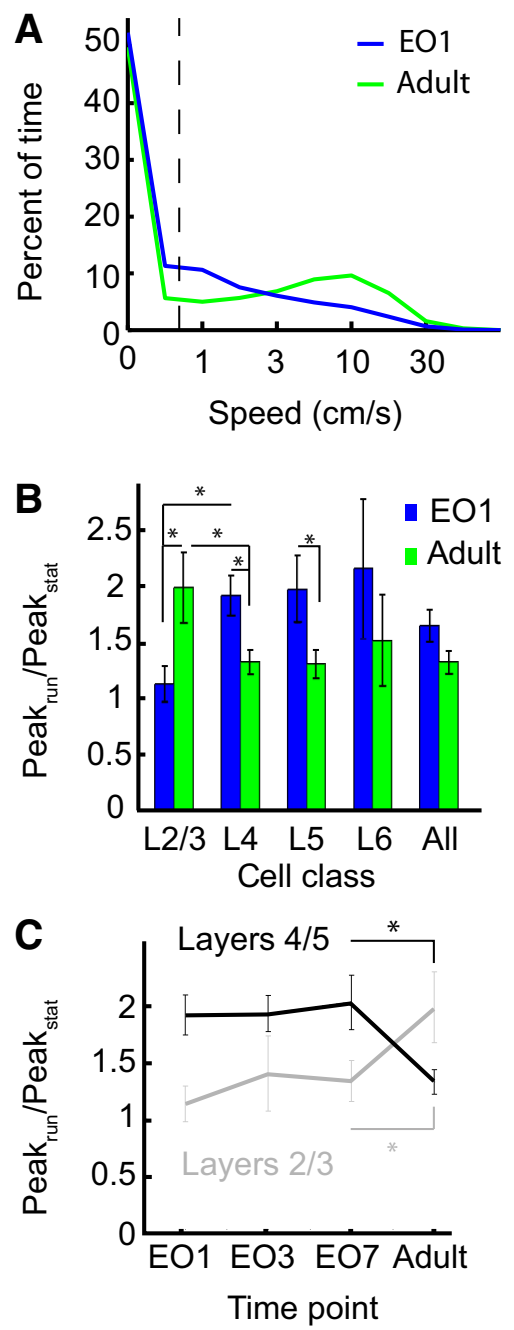

Figure 12. Locomotor behavior and locomotion-induced modulation of firing rate over development. $\boldsymbol{A}$, Distribution of all recorded ball speeds from E01 juveniles (blue) and adults (green). These two distributions were significantly different ( $p<0.01$, KS test), and both deviated from a normal, unimodal distribution (Hartigan's dip test). The gray dashed line indicates the threshold $(0.7 \mathrm{~cm} / \mathrm{s}$ ) that was used to separate the central peak at $\sim 0 \mathrm{~cm} / \mathrm{s}$ (stationary) from the wide distribution of moving speeds (locomotion). $\boldsymbol{B}$, Behavior-dependent modulation of responsiveness segregated by cell class and age. Modulation is shown as the ratio of median peak firing rate during running $\left(\right.$ Peak $_{\text {run }}$ ) relative to the median peak firing rate while stationary $\left(\right.$ Peak $\left._{\text {stat }}\right)$. * $p<0.05$. E01, $n=183$; adult, $n=212$. Confidence intervals are computed via a boostrapping procedure; Wilcoxon's rank-sum test was used to compare differences between groups, Bonferroni's correction. C, Developmental changes in gain from E01 through development comparing layers $2 / 3$ (gray) with layers $4 / 5$ (black). ${ }^{*} p<0.05$, Wilcoxon's rank-sum test, Bonferroni's correction.

as a function of layer (Fig. 14). In the adult, the locomotioninduced increase in power (at $50-60 \mathrm{~Hz}$ ) was observed in layers 2-5 but sharply attenuated in layer 6 (Fig. 14B). In contrast, at eye opening, the locomotion-induced increase (at $20-40 \mathrm{~Hz}$ ) is evident only in layers 4 and 5 (Fig. 14A), consistent with the site of firing rate changes. Therefore, there are distinct patterns of locomotor-induced changes in the LFP power over development that vary as a function of layer. When we analyzed the peak frequency within the range increased by locomotion $(30-60 \mathrm{~Hz})$, we did not observe the fully mature pattern of frequency modulation until after EO7 (Fig. 14C). Similarly, the modulation of the amplitude of the peak signal between 20 and $60 \mathrm{~Hz}$ matured significantly between EO7 and adulthood (Fig. 14D). Thus, although cortical state, as assayed by firing rate changes and oscil- 
latory activity, is already regulated by behavior at eye opening, the pattern of activity changes over development in a layer-specific manner.

\section{Discussion}

A timeline for the development of RF properties across layers of mouse V1 We quantified the normal development of OS, DS, SF preference, and linearity as a function of cortical layer in the quiescent, awake mouse. We find that a significant degree of response selectivity is established at eye opening across all layers of monocular V1. However, several measures of selectivity significantly increase over week 1 after eye opening, and this development is particularly prominent in layers $2-4$. We also provide novel evidence that the development of layers 5 and 6 diverges from layers $2-4$. This suggests that the maturation of basic response selectivity in layers 5 and 6 may be mostly complete at eye opening. Interestingly, features such as a developmental reduction in bias for selectivity along the cardinal axes and enhanced responses to high SF gratings ( $>0.25 \mathrm{cpd}$ ) are observed in nearly every layer and continue to mature after week 1 of eye opening. We observe that these early developmental changes are tightly coupled between cortical layers that share common features of selectivity in adulthood.

Our finding for an early increase in OS (between P14 and P22) is consistent with previous studies examining superficial, monocular V1 (Rochefort et al., 2011; Ko et al., 2013). Interestingly, this increase in OS in monocular V1 precedes that seen in binocular cortex because one study found that the OSI increases for contralateral responses significantly between P21 ( $\sim 1$ week after eye opening) and adulthood (Wang et al., 2013). The same study also reports significant development of binocular matching between simple cells that take places between P21 and P23. Here, we find a significant increase in linearity in monocular V1 over week 1 after eye opening (P12-P21) that directly precedes orientation matching of binocular simple cells. Thus, our study provides an important link in relating the developmental trajectories of V1 function in the monocular and binocular zones. In addition, our finding for a developmental change in DS conflicts with previous observations (Rochefort et al., 2011). Differences in developmental time points examined, alertness, or variability by layer may account for this particular discrepancy, highlighting the importance in generating a more complete characterization of mouse visual cortex development.

Overall, our specific findings compliment other recent work on OS and the development of V1 function in the mouse and suggest that week 1 after eye opening (P14-P21) is particularly important in the initial refinement of many basic RF properties across several layers of V1 (Fagiolini et al., 2003; Wang et al., 2010, 2013; Rochefort et al., 2011; Ko et al., 2014). In addition, we also find that some developmental changes occur in monocular V1 over a time period that coincides with the onset of the classical critical period for OD plasticity and orientation preference matching (Hensch et al., 1998; Antonini et al., 1999; Wang et al., 2010). Importantly, this overall developmental trajectory mirrors classical studies in other models of visual system development. In cats, monkeys, and ferrets, selectivity for orientation is established at eye opening but undergoes significant refinement over a defined period thereafter (Wiesel and Hubel, 1963; Blakemore and Van Sluyters, 1975; Frégnac and Imbert, 1978; Imbert et al., 1978; Chapman and Stryker, 1993; Krug et al., 2001; White et al., 2001). However, the mechanisms that underlie this initial establishment and refinement of RF selectivity remain unclear and may vary by species.

\section{The possible role of selective subcortical input in shaping cortical response selectivity}

Recent evidence has suggested a dedicated circuit that links direction- and orientation-selective retinal ganglion cell responses to superficial layers of V1 (Cruz-Martín et al., 2014). It has been proposed that this subcortical selectivity may contribute substantially to the selectivity that is observed in mature V1 (Tan et al., 2011; Clemens et al., 2012; Cruz-Martín et al., 2014). However, there are distinct hallmarks of this subcortical selectivity that differentiate it from the type of selectivity that dominates in V1. In particular, OS/DS cells in the LGN, which are a minority of the population, are generally nonlinear (ON/OFF) with a concentric RF (Wang et al., 2010; Piscopo et al., 2013; Zhao et al., 2013a,b; Sarnaik et al., 2014). In contrast, orientation-selective cells in superficial mouse V1 are generally linear with elongated ON and OFF subregions aligned along their preferred orientation (Niell and Stryker, 2008; Bonin et al., 2011). Notably, the selective responses that we observe at eye opening have these canonical oriented RFs (Fig. 5). This suggests that the majority of neurons in $\mathrm{V} 1$ are not simply recapitulating subcortical selectivity in either the adult or the visually naive juvenile.

However, we do find an interesting parallel between the features of selectivity represented in the retina and the cortex at eye opening. The majority of OS and DS neurons present at eye opening in the cortex are tuned along the cardinal axes. This feature of DS tuning in the early developing mouse cortex was reported previously by 
A
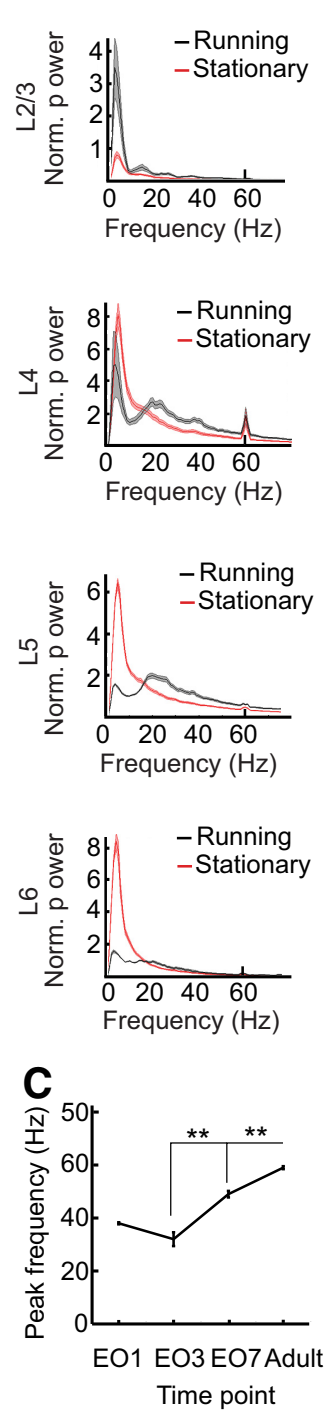
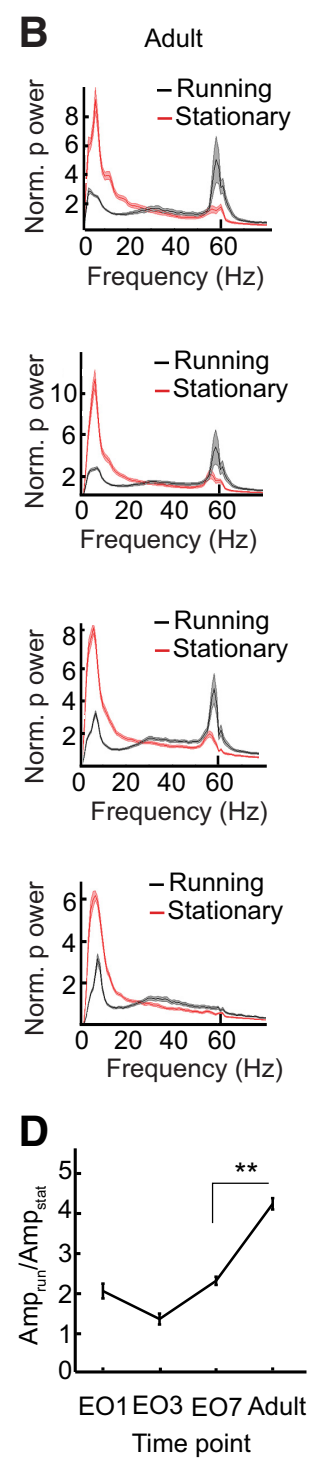

Figure 14. Locomotor-induced modulations of the LFP as a function of layer and development al stage. $A$, Median, normalized LFP power ( $y$-axis) between 2 and $60 \mathrm{~Hz}$ ( $x$-axis) during running (black) and stationary (red) states at E01 segregated by layer. Shaded regions are SEM. $\boldsymbol{B}$, Similar traces as shown in $\boldsymbol{A}$; data are from the adult group. Note the differences in the amplitude and frequency range of peak power modulations and layers in which modulation of power is most prominent (E01, layers 4 and 5 ; adult, layers $2-5)$. C, Median peak frequency within the gamma range $(30-60 \mathrm{~Hz})$ from E01-Adult stages. ${ }^{* *} p<0.01$, Wilcoxon's ranksum test, Bonferroni's correction. $D$, Median of the amplitude during the running state ( $\mathrm{Amp}_{\mathrm{run}}$ ) relative to the median of the amplitude during the stationary state $\left(\mathrm{Amp}_{\mathrm{stat}}\right)$ as a measure of behavioral modulation of the LFP. ${ }^{*} p<0.05,{ }^{* *} p<0.01$. Layers $2-5, n=43$; layer $6, n=28$. Confidence intervals are obtained via a bootstrapping procedure, Wilcoxon's rank-sum test, Bonferroni's correction.

Rochefort et al. (2011). Interestingly, this bias in tuning is a property of DS responses in the retina and LGN (Marshel et al., 2012; Yonehara et al., 2013) and is established before eye opening in the retina (Elstrott et al., 2008; Chen et al., 2009). Thus, although cortical neurons may not directly inherit this tuning from subcortical projections, it raises the possibility that these DS/OS inputs may provide a bias in the initial establishment of RFs.

\section{Maturation of behavioral-state modulation of the cortical circuit}

Locomotion has been shown to exert a powerful effect on cortical processing in the mouse (Niell and Stryker, 2010; Andermann et al., 2011; Keller et al., 2012; Ayaz et al., 2013). Recent studies have suggested that cholinergic input to a disinhibitory circuit mediated by vasointestinal peptide-expressing interneurons may at least partially contribute to this activity (Fu et al., 2014; Lee et al., 2014). However, other modulatory pathways are likely required as well (Polack et al., 2013). Surprisingly, we find that the laminar profile of this effect changes between week 1 after eye opening and adulthood. Early in development, locomotion primarily modulates the firing rate of layers 4 and 5, whereas in adulthood, gain effects are predominantly in layer $2 / 3$. This shift could be attributable to refinement of the modulatory inputs to cortex, changes in the intracortical synaptic connectivity mediating the effects, or both. Interestingly, this behavioral-state effect has been shown to regulate plasticity in the adult (Kaneko and Stryker, 2014). Therefore, it is possible that this could represent a shift in the sites of plasticity within the cortical circuit over development.

At the same time, immature patterns of behavioral modulation of coherent LFP are apparent across layers at EO1 and also do not reach maturity until after EO7 (Figs. 13, 14). Overall, we observe gamma-like modulation responses specifically in layers 4 and 5 at eye opening, whereas strong modulatory effects on LFP are instead observed in layers $2-5$ in the adult. Our finding that behavioral modulation of gamma occurs specifically in layers 4 and 5 at eye opening is consistent with recent work that has reported the existence of a "developmental" gamma oscillation in somatosensory cortex that couples thalamocortical circuits and is generated within the thalamus (Minlebaev et al., 2011).

\section{The development of inhibition and V1 function}

Several important computational roles for broadly tuned feedforward inhibition in V1 have been proposed, including in the development of cortical circuits (Vidyasagar et al., 1996; Sompolinsky and Shapley, 1997; Ferster and Miller, 2000; Bartos et al., 2007; Runyan et al., 2010). In particular, the tuning response of inhibitory interneurons in mouse V1 broadens over the same developmental period that RF property selectivity increases in excitatory neurons (Kuhlman et al., 2011; Li et al., 2012). To assess the relationship between specific classes of inhibition and V1 development across cortical layers, we monitored the emergence and development of narrow waveforms from eye opening. However, we were unable to detect significant numbers of this response type before EO7. By EO7, we are able to detect a significant number of narrow waveforms and find that their OS is already broadly tuned, consistent with the time course observed in previous studies of the broadening of parvalbumin-expressing interneuron tuning over early development (Kuhlman et al., 2011; Li et al., 2012).

In summary, we provide a comprehensive picture of the progressive establishment of multiple key features of V1 function in the mouse as a function of cortical layer. This work will spur future studies to determine the molecular mechanisms underlying the development of cortical visual processing with greater spatial and temporal precision.

\section{References}

Altamura C, Dell'Acqua ML, Moessner R, Murphy DL, Lesch KP, Persico AM (2007) Altered neocortical cell density and layer thickness in serotonin transporter knockout mice: a quantitation study. Cereb Cortex 17:13941401. CrossRef Medline

Andermann ML, Kerlin AM, Roumis DK, Glickfeld LL, Reid RC (2011) Functional specialization of mouse higher visual cortical areas. Neuron 72:1025-1039. CrossRef Medline

Antonini A, Fagiolini M, Stryker MP (1999) Anatomical correlates of func- 
tional plasticity in mouse visual cortex. J Neurosci 19:4388-4406. Medline

Ayaz A, Saleem AB, Schölvinck ML, Carandini M (2013) Locomotion controls spatial integration in mouse visual cortex. Curr Biol 23:890-894. CrossRef Medline

Bartos M, Vida I, Jonas P (2007) Synaptic mechanisms of synchronized gamma oscillations in inhibitory interneuron networks. Nat Rev Neurosci 8:45-56. CrossRef Medline

Batschelet E (1981) Circular statistics in biology. New York: Academic.

Blakemore C, Van Sluyters RC (1975) Innate and environmental factors in the development of the kitten's visual cortex. J Physiol 248:663-716. Medline

Bonin V, Histed MH, Yurgenson S, Reid RC (2011) Local diversity and fine-scale organization of receptive fields in mouse visual cortex. J Neurosci 31:18506-18521. CrossRef Medline

Brainard DH (1997) The psychophysics toolbox. Spat Vis 10:433-436. CrossRef Medline

Cang J, Feldheim DA (2013) Developmental mechanisms of topographic map formation and alignment. Annu Rev Neurosci 36:51-77. CrossRef Medline

Cardin JA, Carlén M, Meletis K, Knoblich U, Zhang F, Deisseroth K, Tsai LH, Moore CI (2009) Driving fast-spiking cells induces gamma rhythm and controls sensory responses. Nature 459:663-667. CrossRef Medline

Chapman B, Stryker MP (1993) Development of orientation selectivity in ferret visual cortex and effects of deprivation. J Neurosci 13:52515262. Medline

Chen M, Weng S, Deng Q, Xu Z, He S (2009) Physiological properties of direction-selective ganglion cells in early postnatal and adult mouse retina. J Physiol 587:819-828. CrossRef Medline

Clarke KA, Still J (2001) Development and consistency of gait in the mouse. Physiol Behav 73:159-164. CrossRef Medline

Clemens JM, Ritter NJ, Roy A, Miller JM, Van Hooser SD (2012) The laminar development of direction selectivity in ferret visual cortex. J Neurosci 32:18177-18185. CrossRef Medline

Cruz-Martín A, El-Danaf RN, Osakada F, Sriram B, Dhande OS, Nguyen PL, Callaway EM, Ghosh A, Huberman AD (2014) A dedicated circuit links direction-selective retinal ganglion cells to the primary visual cortex. Nature 507:358-361. CrossRef Medline

Dehorter N, Michel FJ, Marissal T, Rotrou Y, Matrot B, Lopez C, Humphries MD, Hammond C (2011) Onset of pup locomotion coincides with loss of NR2C/D-mediated cortico-striatal EPSCs and dampening of striatal network immature activity. Front Cell Neurosci 5:24. CrossRef Medline

Dombeck DA, Khabbaz AN, Collman F, Adelman TL, Tank DW (2007) Imaging large-scale neural activity with cellular resolution in awake, mobile mice. Neuron 56:43-57. CrossRef Medline

Elstrott J, Anishchenko A, Greschner M, Sher A, Litke AM, Chichilnisky EJ, Feller MB (2008) Direction selectivity in the retina is established independent of visual experience and cholinergic retinal waves. Neuron 58: 499-506. CrossRef Medline

Fagiolini M, Katagiri H, Miyamoto H, Mori H, Grant SG, Mishina M, Hensch TK (2003) Separable features of visual cortical plasticity revealed by $\mathrm{N}$-methyl-D-aspartate receptor 2A signaling. Proc Natl Acad Sci U S A 100:2854-2859. CrossRef Medline

Ferster D, Miller KD (2000) Neural mechanisms of orientation selectivity in the visual cortex. Annu Rev Neurosci 23:441-471. CrossRef Medline

Frégnac Y, Imbert M (1978) Early development of visual cortical cells in normal and dark-reared kittens: relationship between orientation selectivity and ocular dominance. J Physiol 278:27-44. Medline

Fu Y, Tucciarone JM, Espinosa JS, Sheng N, Darcy DP, Nicoll RA, Huang ZJ, Stryker MP (2014) A cortical circuit for gain control by behavioral state. Cell 156:1139-1152. CrossRef Medline

Harris KD, Henze DA, Csicsvari J, Hirase H, Buzsáki G (2000) Accuracy of tetrode spike separation as determined by simultaneous intracellular and extracellular measurements. J Neurophysiol 84:401-414. Medline

Hartigan JA, Hartigan PM (1985) The dip test of unimodality. Ann Stat 13:70-84. CrossRef

Heeger DJ (1992) Normalization of cell responses in cat striate cortex. Vis Neurosci 9:181-197. CrossRef Medline

Hensch TK, Fagiolini M, Mataga N, Stryker MP, Baekkeskov S, Kash SF (1998) Local GABA circuit control of experience-dependent plasticity in developing visual cortex. Science 282:1504-1508. CrossRef Medline

Hubel DH, Wiesel TN (1962) Receptive fields, binocular interaction and functional architecture in the cat's visual cortex. J Physiol 160:106-154. Medline

Hubel DH, Wiesel TN (1968) Receptive fields and functional architecture of monkey striate cortex. J Physiol 195:215-243. Medline

Huberman AD, Feller MB, Chapman B (2008) Mechanisms underlying development of visual maps and receptive fields. Annu Rev Neurosci 31: 479-509. CrossRef Medline

Imbert M, Buisseret P, Fregnac Y, Gary-Bobo E (1978) Ontogeny of the properties of the cells of the visual cortex of the kitten (in French). Arch Ital Biol 116:370-374. Medline

Jones JP, Palmer LA (1987) The two-dimensional spatial structure of simple receptive fields in cat striate cortex. J Neurophysiol 58:1187-1211. Medline

Kaneko M, Stryker MP (2014) Sensory experience during locomotion promotes recovery of function in adult visual cortex. eLife 3:e02798. CrossRef Medline

Katzner S, Busse L, Carandini M (2011) GABAA inhibition controls response gain in visual cortex. J Neurosci 31:5931-5941. CrossRef Medline

Keller GB, Bonhoeffer T, Hübener M (2012) Sensorimotor mismatch signals in primary visual cortex of the behaving mouse. Neuron 74:809-815. CrossRef Medline

Ko H, Cossell L, Baragli C, Antolik J, Clopath C, Hofer SB, Mrsic-Flogel TD (2013) The emergence of functional microcircuits in visual cortex. Nature 496:96-100. CrossRef Medline

Ko H, Mrsic-Flogel TD, Hofer SB (2014) Emergence of feature-specific connectivity in cortical microcircuits in the absence of visual experience. J Neurosci 34:9812-9816. CrossRef Medline

Krug K, Akerman CJ, Thompson ID (2001) Responses of neurons in neonatal cortex and thalamus to patterned visual stimulation through the naturally closed lids. J Neurophysiol 85:1436-1443. Medline

Kuhlman SJ, Tring E, Trachtenberg JT (2011) Fast-spiking interneurons have an initial orientation bias that is lost with vision. Nat Neurosci 14: 1121-1123. CrossRef Medline

Lee AM, Hoy JL, Bonci A, Wilbrecht L, Stryker MP, Niell CM (2014) Identification of a brainstem circuit regulating visual cortical state in parallel with locomotion. Neuron 83:455-466. CrossRef Medline

Li YT, Ma WP, Pan CJ, Zhang LI, Tao HW (2012) Broadening of cortical inhibition mediates developmental sharpening of orientation selectivity. J Neurosci 32:3981-3991. CrossRef Medline

Marshel JH, Kaye AP, Nauhaus I, Callaway EM (2012) Anterior-posterior direction opponency in the superficial mouse lateral geniculate nucleus. Neuron 76:713-720. CrossRef Medline

Mazurek M, Kager M, Van Hooser SD (2014) Robust quantification of orientation selectivity and direction selectivity. Front Neural Circuits 8:92. CrossRef Medline

Mechler F, Ringach DL (2002) On the classification of simple and complex cells. Vis Res 42:1017-1033. CrossRef Medline

Minlebaev M, Colonnese M, Tsintsadze T, Sirota A, Khazipov R (2011) Early gamma oscillations synchronize developing thalamus and cortex. Science 334:226-229. CrossRef Medline

Mitra P, Bokil H (2007) Observed brain dynamics. New York: Oxford UP.

Mitra PP, Pesaran B (1999) Analysis of dynamic brain imaging data. Biophys J 76:691-708. CrossRef Medline

Morishita H, Hensch TK (2008) Critical period revisited: impact on vision. Curr Opin Neurobiol 18:101-107. CrossRef Medline

Niell CM, Stryker MP (2008) Highly selective receptive fields in mouse visual cortex. J Neurosci 28:7520-7536. CrossRef Medline

Niell CM, Stryker MP (2010) Modulation of visual responses by behavioral state in mouse visual cortex. Neuron 65:472-479. CrossRef Medline

Pelli DG (1997) The VideoToolbox software for visual psychophysics: transforming numbers into movies. Spat Vis 10:437-442. CrossRef Medline

Piscopo DM, El-Danaf RN, Huberman AD, Niell CM (2013) Diverse visual features encoded in mouse lateral geniculate nucleus. J Neurosci 33:46424656. CrossRef Medline

Polack PO, Friedman J, Golshani P (2013) Cellular mechanisms of brain state-dependent gain modulation in visual cortex. Nat Neurosci 16:13311339. CrossRef Medline

Ringach DL (2002) Spatial structure and symmetry of simple-cell receptive fields in macaque primary visual cortex. J Neurophysiol 88:455-463. Medline

Ringach DL, Shapley RM, Hawken MJ (2002) Orientation selectivity in ma- 
caque V1: diversity and laminar dependence. J Neurosci 22:5639-5651. Medline

Rochefort NL, Narushima M, Grienberger C, Marandi N, Hill DN, Konnerth A (2011) Development of direction selectivity in mouse cortical neurons. Neuron 71:425-432. CrossRef Medline

Runyan CA, Schummers J, Van Wart A, Kuhlman SJ, Wilson NR, Huang ZJ, Sur M (2010) Response features of parvalbumin-expressing interneurons suggest precise roles for subtypes of inhibition in visual cortex. Neuron 67:847-857. CrossRef Medline

Sarnaik R, Wang BS, Cang J (2014) Experience-dependent and independent binocular correspondence of receptive field subregions in mouse visual cortex. Cereb Cortex 24:1658-1670. CrossRef Medline

Schmitzer-Torbert N, Jackson J, Henze D, Harris K, Redish AD (2005) Quantitative measures of cluster quality for use in extracellular recordings. Neuroscience 131:1-11. CrossRef Medline

Sirota A, Montgomery S, Fujisawa S, Isomura Y, Zugaro M, Buzsáki G (2008) Entrainment of neocortical neurons and gamma oscillations by the hippocampal theta rhythm. Neuron 60:683-697. CrossRef Medline

Skottun BC, De Valois RL, Grosof DH, Movshon JA, Albrecht DG, Bonds AB (1991) Classifying simple and complex cells on the basis of response modulation. Vision Res 31:1079-1086. Medline

Sompolinsky H, Shapley R (1997) New perspectives on the mechanisms for orientation selectivity. Curr Opin Neurobiol 7:514-522. CrossRef Medline

Tan AY, Brown BD, Scholl B, Mohanty D, Priebe NJ (2011) Orientation selectivity of synaptic input to neurons in mouse and cat primary visual cortex. J Neurosci 31:12339-12350. CrossRef Medline

Trachtenberg JT, Stryker MP (2001) Rapid anatomical plasticity of horizontal connections in the developing visual cortex. J Neurosci 21:3476-3482. Medline
Trachtenberg JT, Trepel C, Stryker MP (2000) Rapid extragranular plasticity in the absence of thalamocortical plasticity in the developing primary visual cortex. Science 287:2029-2032. CrossRef Medline

Triplett JW (2014) Molecular guidance of retinotopic map development in the midbrain. Curr Opin Neurobiol 24:7-12. CrossRef Medline

Vidyasagar TR, Pei X, Volgushev M (1996) Multiple mechanisms underlying the orientation selectivity of visual cortical neurones. Trends Neurosci 19:272-277. CrossRef Medline

Wang BS, Sarnaik R, Cang J (2010) Critical period plasticity matches binocular orientation preference in the visual cortex. Neuron 65:246-256. CrossRef Medline

Wang BS, Feng L, Liu M, Liu X, Cang J (2013) Environmental enrichment rescues binocular matching of orientation preference in mice that have a precocious critical period. Neuron 80:198-209. CrossRef Medline

White LE, Coppola DM, Fitzpatrick D (2001) The contribution of sensory experience to the maturation of orientation selectivity in ferret visual cortex. Nature 411:1049-1052. CrossRef Medline

Wiesel TN, Hubel DH (1963) Effects of visual deprivation on morphology and physiology of cells in the cats lateral geniculate body. J Neurophysiol 26:978-993. Medline

Yonehara K, Farrow K, Ghanem A, Hillier D, Balint K, Teixeira M, Jüttner J, Noda M, Neve RL, Conzelmann KK, Roska B (2013) The first stage of cardinal direction selectivity is localized to the dendrites of retinal ganglion cells. Neuron 79:1078-1085. CrossRef Medline

Zhao X, Liu M, Cang J (2013a) Sublinear binocular integration preserves orientation selectivity in mouse visual cortex. Nat Commun 4:2088. CrossRef Medline

Zhao X, Chen H, Liu X, Cang J (2013b) Orientation-selective responses in the mouse lateral geniculate nucleus. J Neurosci 33:12751-12763. CrossRef Medline 